\title{
Investigation of Optimum Polymerization Conditions for Synthesis of Cross-Linked Polyacrylamide-Amphoteric Surfmer Nanocomposites for Polymer Flooding in Sandstone Reservoirs
}

\author{
A. N. El-hoshoudy, ${ }^{1}$ S. E. M. Desouky, ${ }^{1}$ M. Y. Elkady, ${ }^{2}$ A. M. Alsabagh, ${ }^{1}$ \\ M. A. Betiha, ${ }^{1}$ and S. Mahmoud ${ }^{1}$ \\ ${ }^{1}$ Egyptian Petroleum Research Institute, Nasr City, Cairo 11727, Egypt \\ ${ }^{2}$ Department of Chemistry, Faculty of Science, Ain shams University, Cairo, Egypt
}

Correspondence should be addressed to A. N. El-hoshoudy; azizchemist@yahoo.com

Received 27 May 2015; Revised 22 July 2015; Accepted 22 July 2015

Academic Editor: Qinglin Wu

Copyright ( 2015 A. N. El-hoshoudy et al. This is an open access article distributed under the Creative Commons Attribution License, which permits unrestricted use, distribution, and reproduction in any medium, provided the original work is properly cited.

\begin{abstract}
Currently enhanced oil recovery (EOR) technology is getting more attention by many countries since energy crises are getting worse and frightening. Polymer flooding by hydrophobically associated polyacrylamides (HAPAM) and its modified silica nanocomposite are a widely implemented technique through enhanced oil recovery (EOR) technology. This polymers class can be synthesized by copolymerization of acrylamide (AM), reactive surfmer, functionalized silica nanoparticles, and a hydrophobic cross-linker moiety in the presence of water soluble initiator via heterogeneous emulsion polymerization technique, to form latexes that can be applied during polymer flooding. Chemical structure of the prepared copolymers was proven through different techniques such as Fourier transform infrared spectroscopy (FTIR), and nuclear magnetic spectroscopy $\left({ }^{1} \mathrm{H} \&{ }^{13} \mathrm{C}-\mathrm{NMR}\right)$, and molecular weight was measured by gel permeation chromatography. Study of the effects of monomer, surfmer, cross-linker, silica, and initiator concentrations as well as reaction temperature was investigated to determine optimum polymerization conditions through single factor and orthogonal experiments. Evaluation of the prepared copolymers for enhancing recovered oil amount was evaluated by carrying out flooding experiments on one-dimensional sandstone model to determine recovery factor.
\end{abstract}

\section{Introduction}

Crude oil is the most critical energy source in the world, especially for transportation and provision of heat and light as there has not been a sufficient energy source to replace crude oil which has been broadly integrated [1]. Crude oil production from sandstone and carbonate rock formations occurs in three distinct phases [2]. Primary oil recovery combines the native energy of the reservoir such as dissolved gas drive, natural water drive aquifer, gas cap, and gravity drainage with pumping equipment to bring the oil from the reservoir into the wellbore and up to the surface, recovering about $~ 15 \%$ OOIP [3]. In secondary oil recovery, as the reservoir loses its energy, an external fluid such as water or gas is injected into the reservoir to maintain reservoir pressure and extend its lifetime to drive hydrocarbons towards the wellbore and then to production wells recovering an additional $\sim 30 \%$ OOIP. The process continues until the water-oil ratio at the production wells becomes very high (oil cut $\leq 1 \%$ ). After water flooding, there is a significant oil amount $\sim 55 \%$ OOIP still trapped in the pores of reservoir rock due to both microscopic and macroscopic factors and it cannot be further removed without the use of enhanced oil recovery (EOR) technologies [1]. The frightening situation of energy shortage imposed the urgent need for recovering more crude oil through EOR applications which comprise different techniques [4]; one of them is polymer flooding through hydrophobically associated polyacrylamide polymers (HAPAM) which are commonly used in enhanced oil recovery $[5,6]$ due to their unique structures and properties, including their thickening 
properties, shear thinning, and antipolyelectrolyte behavior as mobility control agents and rheology modifiers [7]. These polymers are synthesized by free radical emulsion polymerization process through grafting or incorporating hydrophobic chain cross-linking segments onto their hydrophilic main chain $[8,9]$ or by copolymerization of hydrophilic and hydrophobic monomers [10]. Another EOR-flooding agent is hydrophobically associated polyacrylamide-silica nanocomposites (HAPAM-SiO ${ }_{2}$ ) which are synthesized by grafting of silica modified surfaces on polymer backbone structure.

Several polymer field projects have been referenced or reported in the literature. Vossoughi and Buller and Manrique et al. $[11,12]$ reported some advantages in using anionic polyacrylamide/acrylic acid (PAM/AA) in tests carried out on sandpacks and native cores from the Richfield East Dome Unit (REDU) in California. Dabbous [13] conducted the flood tests in heterogeneous porous media showing that preinjection of polymer could result in better flooding efficiency. Platt and James [14] prepared poly(alpha-alkoxy) acrylamides and claimed improved stability in brine solutions. Similar claims were made by Hunter [15] and Cao et al. [16] who prepared $\mathrm{N}$-substituted PAM/AA via ethoxylation. Murduchowitz [17] disclosed terpolymers of acrylamide, acrylonitrile, and acrylic acid [18]. McCormick et al. [19] copolymerize sulfonated monomers such as 2-acrylamido-2-methylpropane sulfonic acid (AMPS) with acrylamide monomers, which provide a somewhat improved calcium ion tolerance. Du and Guan [20] also discuss the field application of polymer flooding. Zou et al. [21] and Mahdavian et al. [22] reported the preparation of multidispersed $\mathrm{SiO}_{2}$ nanocomposites which have enhanced salt-tolerance behavior. Yang-Chuan et al. [23] reported the preparation of monodispersed nano- $\mathrm{SiO}_{2}$ particles by sol-gel method used as inorganic phase and modified by 3-methacryloxypropyltrimethoxysilane (MPS) with active double bond, and then novel nanocomposites of polyacrylamide copolymers with monodisperse $\mathrm{SiO}_{2}$ particles were in situ prepared. It was expected that these nanocomposite solutions effectively improved oil or heavy oil recovery. Flaaten et al. [24] and Zhang et al. [25] discussed the potential application of the nanoparticles stabilized emulsion system in petroleum industry. Ju and Fan [26] have used two types of polysilicon nanoparticles in oil fields to improve oil recovery and enhance water injection.

Polymer flooding aims to increase viscosity of aqueous phase and so decrease mobility ratio less than unity $(M \leq$ 1 ), which in turn improves sweeping efficiency. One of the routine screening parameters used for a preliminary analysis of a reservoir is the mobility ratio that represents effects of relative permeability and viscosity of water and oil on mobility based on Darcy's law (1) as follows [27]:

$$
M=\frac{\lambda_{W}}{\lambda_{O}}=\frac{K_{W} / \mu_{W}}{K_{O} / \mu_{O}}=\frac{K_{W} \mu_{O}}{K_{O} \mu_{W}},
$$

where $M$ is mobility ratio; $\lambda_{W}$ is water phase mobility; $\lambda_{O}$ is oil phase mobility; $K_{W}$ is relative permeability of water phase, $\mathrm{mD} ; K_{O}$ is relative permeability of oil phase, $\mathrm{mD}$; $\mu_{W}$ is water phase viscosity, cp; $\mu_{O}$ is oil phase viscosity, cp. Consequently, we can conclude that, by increasing of polymer viscosity, aqueous phase viscosity will increase and mobility ratio decreases, enhancing sweeping efficiency which in turn increases recovered oil amount.

Polymeric surfactants (surfmers) are functional surfactants, have amphiphilic structure [28], and contain polymerizable vinyl double bonds [29] in their molecular architecture resulting in novel physicochemical properties distinct from conventional surfactants [30] and can be copolymerized with double bond containing monomers. During emulsion polymerization process, the ingredients concentration greatly affects polymerization behavior. To obtain the optimum polymerization conditions through synthesis of these polymers, the effects of acrylamide (AM) monomer concentration, surfmers concentration, initiator concentration, hydrophobic cross-linker moiety, and silica amount were investigated by single variable method [31]. First, we kept the loadings of acrylamide (AM) monomer at $1.69 \mathrm{molL}^{-1}$, cross-linker at $1.14 * 10^{-2} \mathrm{molL}^{-1}$, and the initiator concentration at $6.07 *$ $10^{-3} \mathrm{molL}^{-1}$ and reaction time adjusted for 12 hours at reaction temperature of $60^{\circ} \mathrm{C}$ and then change surfmer concentration to investigate its influence on polymerization by observing the apparent viscosity. On the basis of the aforementioned approach, the effects of other factors on polymerization were studied [32]. At the same time, orthogonal experiments [33] which reveal the complex cause-effect relationship between design parameters and performance are carried out. Orthogonal arrays are special scientific method that requires only a small number of experimental trials to discover main factor effects based on the statistical findings [34]. Evaluation of these polymers for increasing recovered oil amount was done through one-dimensional sandstone packed model, where recovery factor was calculated on volume basis via mass balance equation after primary and secondary methods had been exhausted.

\section{Experimental}

2.1. Materials. They are as follows: 4-dodecyl benzene sulfonic acid (DBSH, mixture of isomers, $\geq 95 \%$ ), 1-vinylimidazole $(\geq 99 \%)$, ethyl acetate $\left(\mathrm{CH}_{3} \mathrm{COOC}_{2} \mathrm{H}_{5}, \geq 99.5 \%\right)$, acrylamide (AM, 99\%) which was twice recrystallized from acetone, dried under vacuum, and stored in the dark at $4^{\circ} \mathrm{C}$ until required, potassium persulfate "KPS" $\left(\mathrm{K}_{2} \mathrm{~S}_{2} \mathrm{O}_{8}, \geq 99 \%\right)$, divinyl sulfone (DVS, $\geq 97 \%$ ), (3-aminopropyl)triethoxysilane $(\geq 98 \%)$, acetone $\left(\mathrm{CH}_{3} \mathrm{COCH}_{3}, \geq 97 \%\right)$, and methanol $\left(\mathrm{CH}_{3} \mathrm{OH}, \geq 97 \%\right)$. All reagents and materials of the best grade available were used without additional purification, supplied from Sigma-Aldrich Chemie GmbH. All aqueous solutions were prepared using deionized or Milli-Q water.

\subsection{Synthesis}

2.2.1. Preparation of Surfmer (4-Dodecyl-benzenesulfonate1-vinylimidazol-3-ium). The addition reaction was carried out in a $250 \mathrm{~mL}$ three-necked Erlenmeyer flask equipped with reflux condenser, mechanical stirrer, and nitrogen inlet/ outlet. To a stirred solution of $34.68 \mathrm{~g}, 0.106 \mathrm{~mol}$ of 4 -dodecyl benzene sulfonic acid in ethyl acetate $(150 \mathrm{~mL})$, under inert nitrogen atmosphere, 1-vinylimidazole $(10 \mathrm{~g}, 0.106 \mathrm{~mol})$ was 

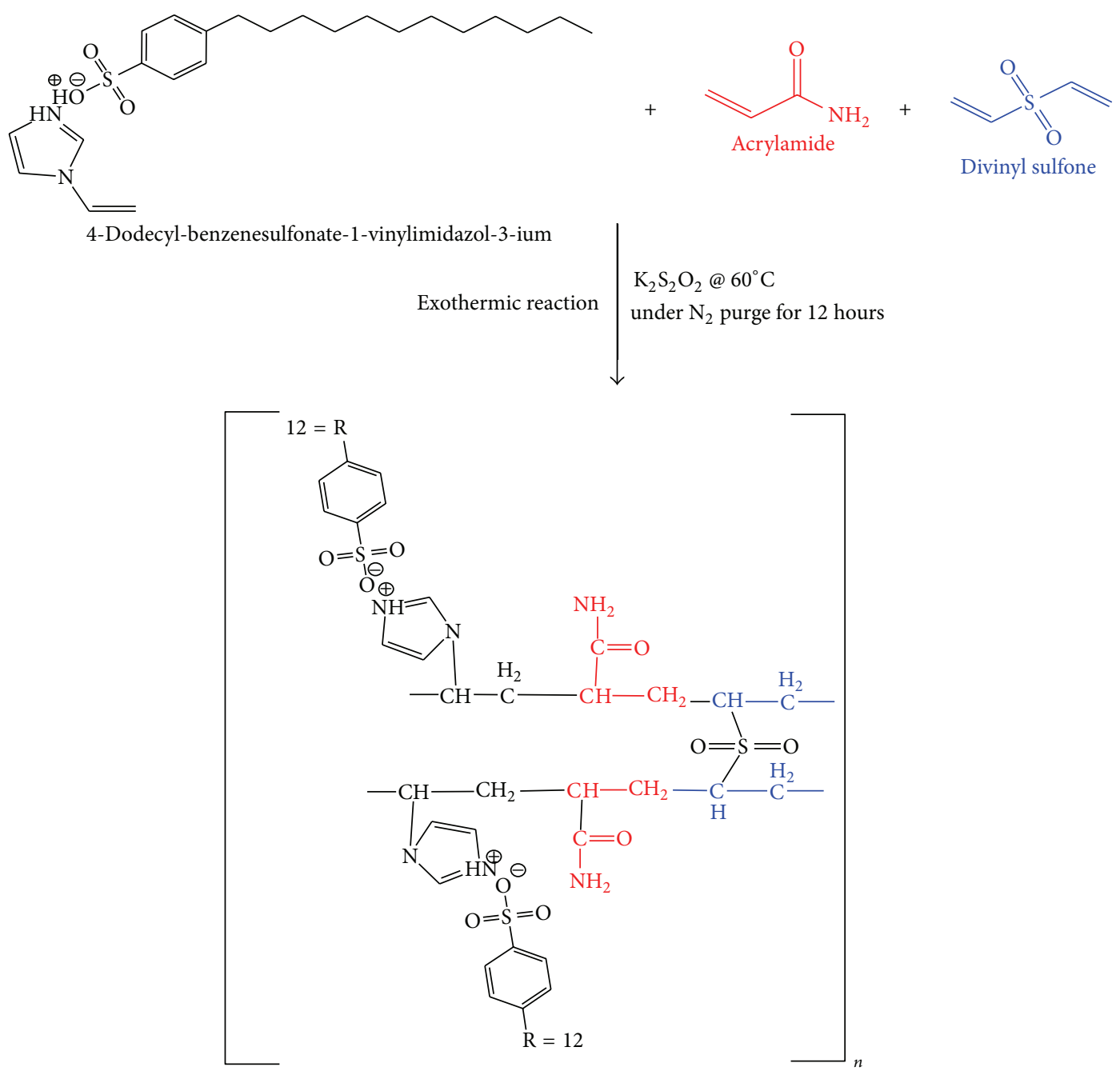

Figure 1: Chemical structure of HAPAM copolymer.

added dropwise under vigorous stirring in ice bath. The solution was maintained at $0^{\circ} \mathrm{C}$ for $2 \mathrm{~h}$ and then stirred for $12 \mathrm{~h}$ at $45^{\circ} \mathrm{C}$. The white product was precipitated by lowering temperature to $-16^{\circ} \mathrm{C}$ and recrystallized through redissolving in $50 \mathrm{~mL}$ ethyl acetate and cooling. The yield was about $73 \%$.

2.2.2. Preparation of HAPAM Copolymer. An aqueous solution of acrylamide in distilled water was gently bubbled with nitrogen gas for $30 \mathrm{~min}$ to remove dissolved oxygen (free radical scavenger). The emulsion polymerization was carried out in a jacketed autoclave equipped with mechanical stirrer, automated temperature controlling unit, and nitrogen inlet/outlet. The designated amounts of acrylamide monomer, hydrophobic divinyl sulfone cross-linker, and surfmer were added into the mixture, stirred vigorously until a clear solution was obtained. The reaction was started by injecting potassium persulfate $\left(\mathrm{K}_{2} \mathrm{~S}_{2} \mathrm{O}_{8}\right)$ as an initiator when reaction temperature was reached, and the reaction mixture was stirred for 12 hours under a nitrogen purge for 1-1.5 hours. Concentrations of initiator, monomer, cross-linker, surfmer, and reaction conditions had been investigated. At the end of the reaction, the viscous polymer gel was precipitated in acetone, redissolved in water, and reprecipitated in acetone, and then subjected to Soxhlet extraction with methanol for $24 \mathrm{~h}$ in order to remove unreacted monomers until a white block solid is obtained. Finally, the solid copolymer was further crushed and vacuum-dried at $60^{\circ} \mathrm{C}$ for 24 hours and then stored in a desiccator.

2.2.3. Preparation of HAPAM-SiO ${ }_{2}$ Nanocomposite. After determination of optimum polymerization conditions and optimum reactants concentration, (3-aminopropyl)triethoxysilane was added in different molar ratios. The polymerization procedure was carried out typically as reported previously in Section 2.2.2. The synthesis and chemical reaction of HAPAM and HAPAM-SiO ${ }_{2}$ are expected to be as illustrated in Figures 1 and 2, respectively.

2.3. Characterization and Equipment. Critical micelle concentration $(\mathrm{Cmc})$ of the prepared surfmer was determined from surface tension measurements by du Noüy ring tensiometer. Viscosity of polymer solution was measured on 


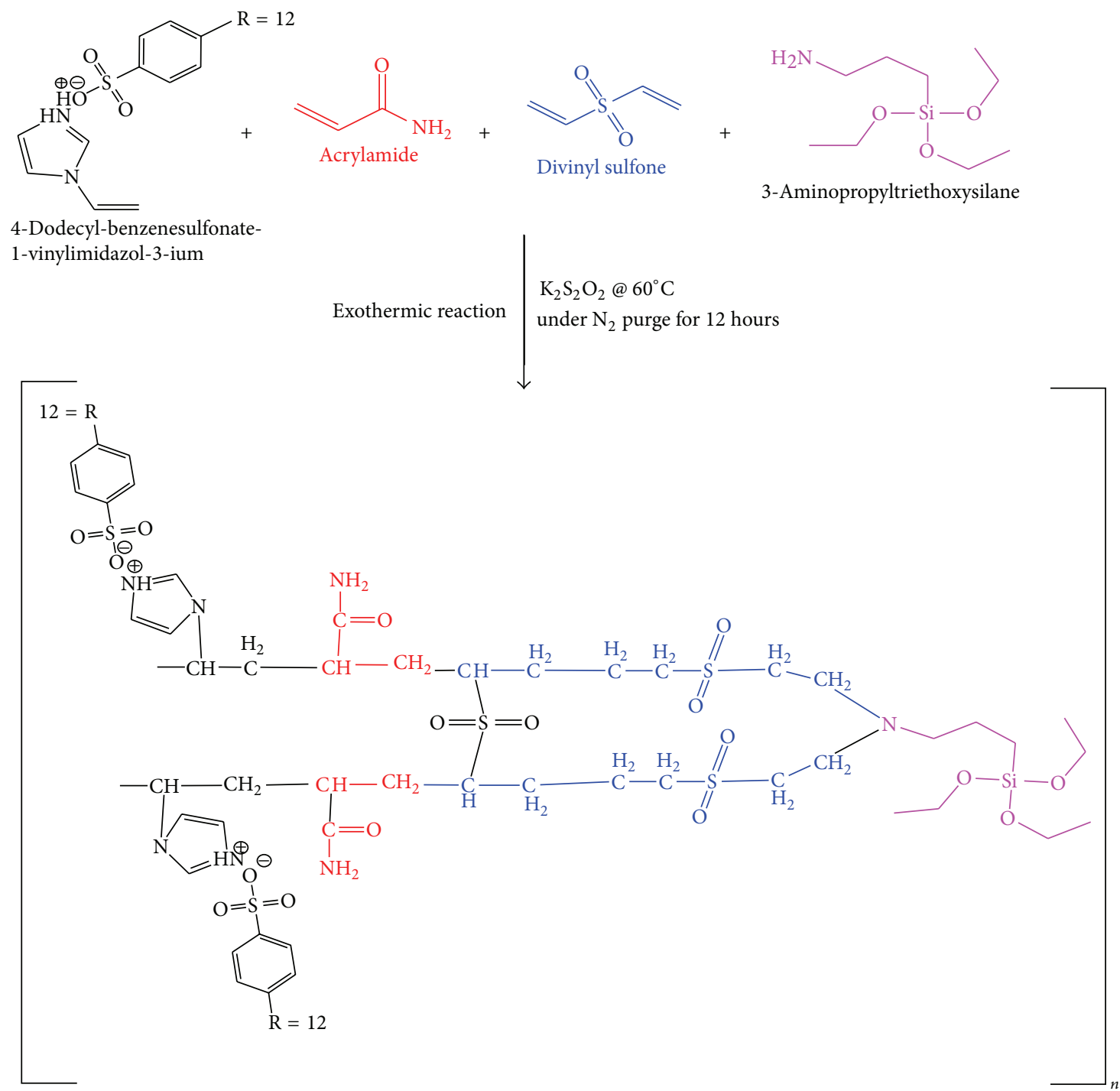

Figure 2: Chemical structure of HAPAM-SiO ${ }_{2}$ nanocomposite.

Brookfield programmable DV-II ${ }^{+}$viscometer, equipped with LV (SC4-25) adapter spindle cone/plate geometry (diameter $=60 \mathrm{~mm}$, angle $=1^{\circ}$, and plate-to-plate gap $=0.104 \mathrm{~mm}$ ). FTIR spectrometric analysis was carried on American FTS3000 infrared spectrometer in the optical range of 600$4000 \mathrm{~cm}^{-1}$ by the averaging of 32 scans at a resolution of $4 \mathrm{~cm}^{-1}$ with $\mathrm{KBr}$ pellets. ${ }^{1} \mathrm{H}-\mathrm{NMR}$ was measured with a Bruker EMX $400 \mathrm{MHz}$ NMR spectrometer (Billerica, MA, USA). The spectrum was recorded after accumulating 32 scans, using $\mathrm{D}_{2} \mathrm{O}$ as a solvent and tetramethylsilane (TMS) as internal standard. The molecular weight was measured by gel permeation chromatography (GPC) using a Waters 600E system controller equipped with a Waters 610 fluid unit pump and a Waters 410 differential refractometer detector.

2.4. Flooding Experiments. Flooding tests were carried out on one-dimensional sandstone model developed by our PVT-lab as shown in Figure 3 to simulate flooding process on reservoir scale [35]. The sand was firstly saturated by brine followed by oil flooding and then copolymer solution with different concentrations was flooded to determine recovery factor.

\section{Results and Discussions}

3.1. Characterization and Structure Determination. IR analysis was performed to determine the structure of the HAPAM copolymer and HAPAM- $\mathrm{SiO}_{2}$ nanocomposite as reported in Figure 4 with their characteristic peaks as follows: HAPAM show strong absorption peaks at 3445-3196 and $1715.62 \mathrm{~cm}^{-1}$; these were attributed to the stretching vibrations of $(\mathrm{N}-\mathrm{H}$ and $\mathrm{C}=\mathrm{O})$ bonds, respectively, in the $\left(-\mathrm{CONH}_{2}\right)$ group [36]. The absorption peaks at 1323 and 1044 correspond to stretching vibration of $(\mathrm{S}=\mathrm{O})$ in sulfones; this indicated that the divinyl sulfone was successfully introduced into the macromolecule chain. The stretching vibration of $(\mathrm{C}=\mathrm{C})$ disappeared within the range of $1600-1680 \mathrm{~cm}^{-1}$. Thus, we can conclude that 


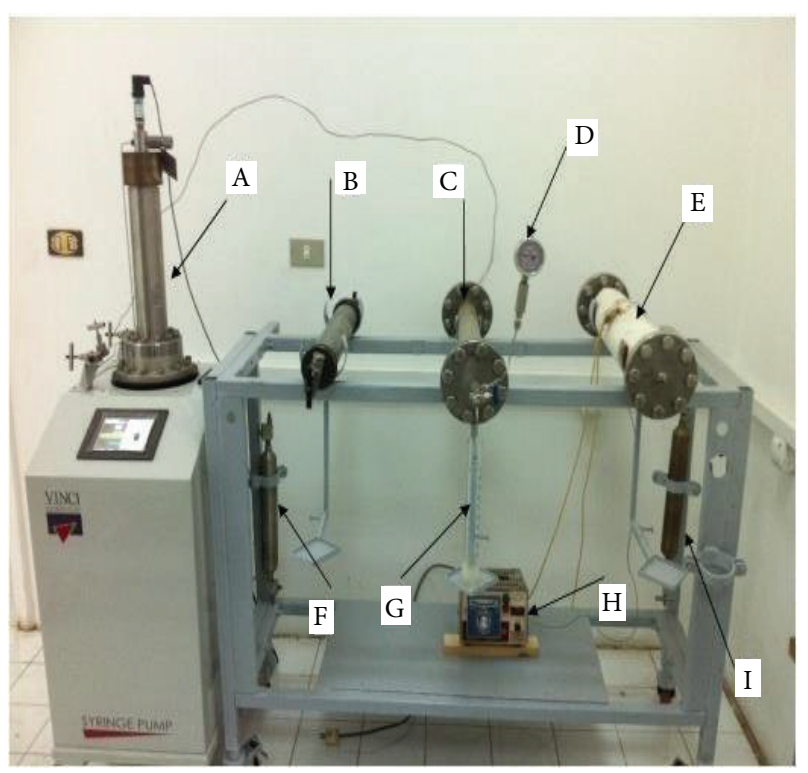

FIGURE 3: Displacement flood apparatus (A: pump; B: brine solution; C: sandstone holder; D: pressure gauge; E: sandstone holder with heating jacket; F: HAPAM solution; G: measuring cylinder; $\mathrm{H}$ : electrical heating unit; I: HAPAM solution).

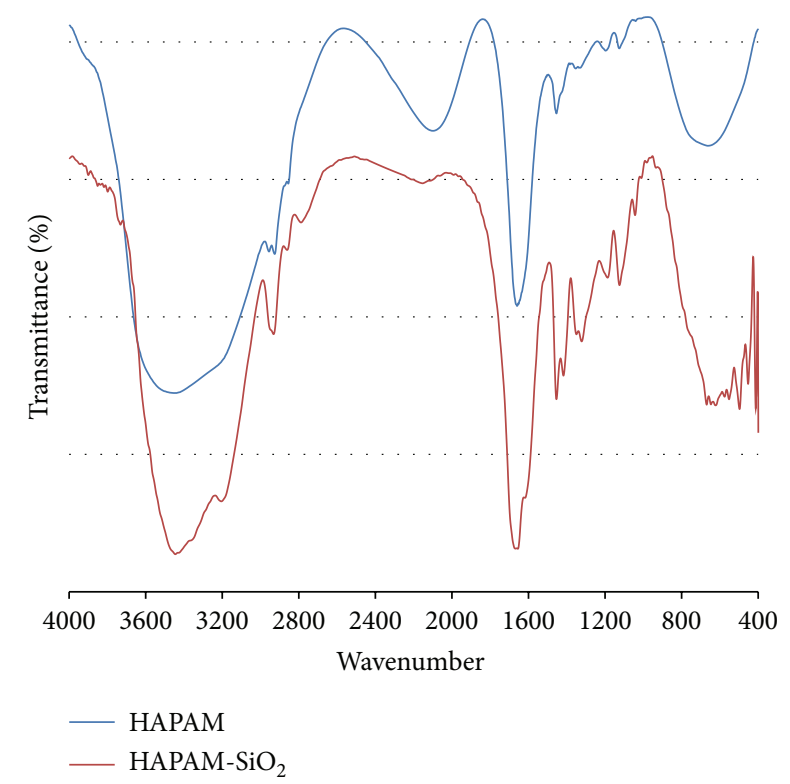

FIGURE 4: FTIR of HAPAM and HAPAM-SiO ${ }_{2}$.

the acrylamide monomer copolymerized with divinyl sulfone and surfmer in the presence of KPS as water soluble initiator to form the proposed structures. HAPAM-SiO ${ }_{2}$ show the same characteristic peaks of HAPAM in addition to characteristic peaks of silica network, where absorption peaks at $1258-1043,924$ and $680 \mathrm{~cm}^{-1}$ are attributed to asymmetric, symmetric stretching vibrations and winding vibration of (Si-O-Si) in the silica network, respectively [37]. Thus we can conclude that silica is introduced in polymer skeleton structure.
TABLE 1: Surface tension $\left(\mathrm{mN} \mathrm{m}^{-1}\right)$ values of prepared surfmer.

\begin{tabular}{lc}
\hline Concentration, $\mathrm{molL}^{-1}$ & Surface tension $\left(\mathrm{mN} \mathrm{m}^{-1}\right)$ \\
\hline 0.0238 & 31 \\
0.0119 & 31 \\
0.0059 & 31 \\
0.0030 & 31 \\
$0.0015^{*}$ & $31^{*}$ \\
0.0007 & 35 \\
0.0004 & 37 \\
0.0002 & 38.5 \\
0.0001 & 39
\end{tabular}

${ }^{*} \mathrm{Cmc}$ value.

Since IR spectrum alone does not give complete information concerning chemical structure, proton ${ }^{1} \mathrm{H}-\mathrm{NMR}$ spectrum of the prepared HAPAM and HAPAM- $\mathrm{SiO}_{2}$ is shown in Figure 5 with their chemical shifts.

${ }^{1} \mathrm{H}$-NMR $\left(400 \mathrm{MHz}, \mathrm{D}_{2} \mathrm{O}, 25^{\circ} \mathrm{C}\right)$ of HAPAM and HAPAM$\mathrm{SiO}_{2}$ and chemical shift signal at $\delta=4.70 \mathrm{ppm}$ can be ascribed as the $\left(\mathrm{NH}_{2}\right)$ of the acrylamide chains. The signals at about $3.59 \mathrm{ppm}$ can be assigned to $\left(-\mathrm{CH}_{2}-\mathrm{Ph}-\right)$ and peaks at around 2.64 and $1.64 \mathrm{ppm}$ represent the $\left(-\mathbf{C H}_{2}\right)$ and $(-\mathrm{CH})$ of the HAPAM, respectively. The peaks from 1.26 to $1.08 \mathrm{ppm}$ can be assigned to $\left(-\mathbf{C H}_{2}\right)$ and $\left(-\mathbf{C H}_{3}\right)$ of $4-$ Dodecyl-benzenesulfonate-1-vinylimidazol-3-ium. In case of HAPAM- $\mathrm{SiO}_{2}$, it was observed that the peaks at 2.64 and $1.64 \mathrm{ppm}$ were shifted slightly to the left because of the silane derivatives and silica. Accordingly, the results confirmed that the nanocomposites were successfully synthesized due to the absence of characteristic band $\left(-\mathrm{CH}_{2}=\mathrm{CH}-\right)$ of acrylamide group and the presence of new peaks at 2.64 and $1.64 \mathrm{ppm}$.

According to the analysis of FTIR and ${ }^{1} \mathrm{H}-\mathrm{NMR}$ spectra, the proposed chemical structures of HAPAM and HAPAM$\mathrm{SiO}_{2}$ are predicted to be as shown previously in Figures 1 and 2 , respectively.

3.2. Molecular Weights of the Prepared Polymers. The molecular weights of the prepared HAPAM and HAPAM- $\mathrm{SiO}_{2}$ were measured by gel permeation chromatography (GPC) instrument (Waters Co., USA). The GPC method shows molecular weights of 1.19 and $0.93 \times 10^{6} \mathrm{gmol}^{-1}$ for HAPAM and $\mathrm{HAPAM}-\mathrm{SiO}_{2}$, respectively.

3.3. Critical Micelle Concentration $(\mathrm{Cmc})$. Cmc of the prepared surfmer (4-dodecyl-benzenesulfonate-1-vinylimidazol-3-ium) was determined from measuring the variation in surface tension $(\gamma)$ with concentration at $60^{\circ} \mathrm{C}$, where the surface tension decreases linearly with increasing concentration and then levels off. The results are summarized in Table 1 , where $\mathrm{Cmc}$ value was found to be $0.001485 \mathrm{molL}^{-1}$.

3.4. Single-Factor Experiments. Optimum polymerization conditions were evaluated through single-factor and orthogonal approaches, where the effects of initiator, monomer, 


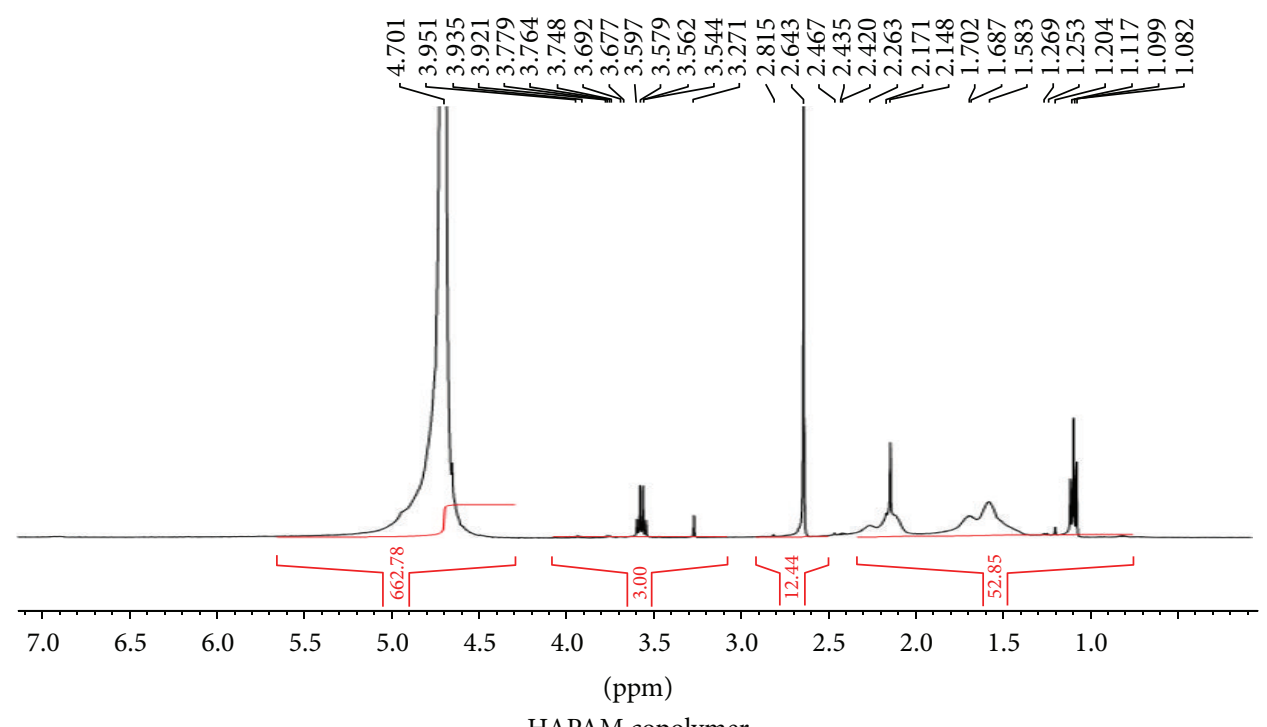

HAPAM copolymer

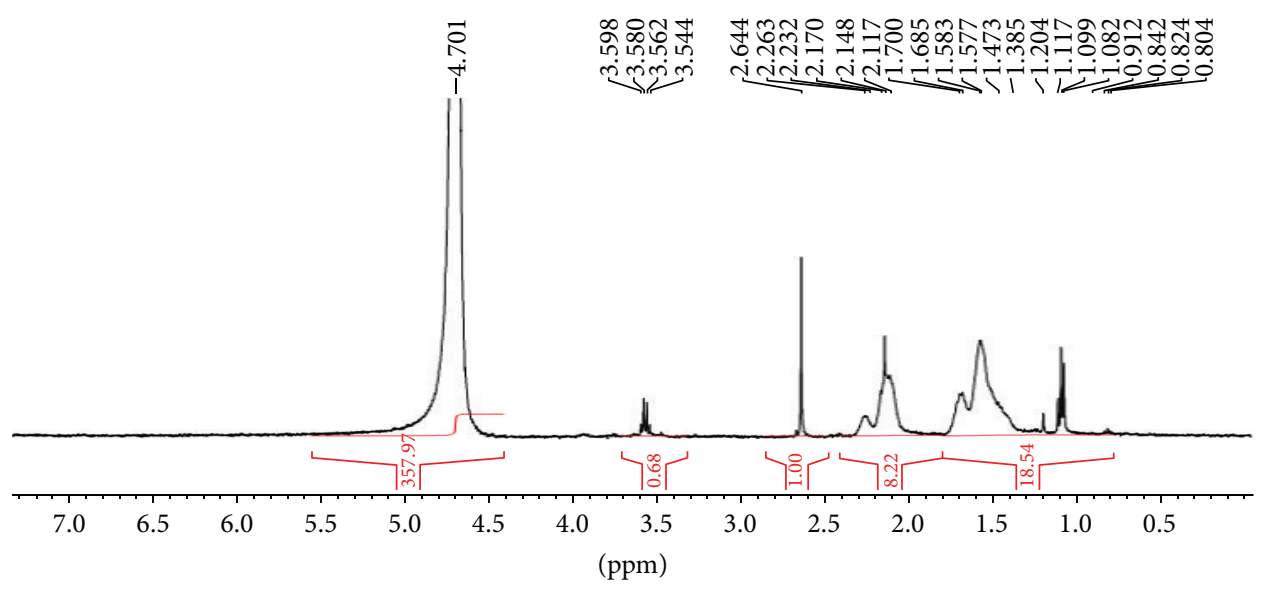

HAPAM- $\mathrm{SiO}_{2}$ nanocomposite

Figure 5: Proton ${ }^{1} \mathrm{H}-\mathrm{NMR}$ spectra of HAPAM and HAPAM-SiO ${ }_{2}$.

cross-linker, surfmer concentrations, and reaction temperature on apparent viscosity were investigated [33] as follows.

3.4.1. Effects of Initiator Concentration. Since dispersion medium of polymerization reaction is water, one should choose one of water soluble initiators such as potassium or ammonium persulfate, hydrogen peroxide, and 2,2-azobis(2amidinopropane) dihydrochloride [38]; in the present study, the authors select $\mathrm{K}_{2} \mathrm{~S}_{2} \mathrm{O}_{8}$ as a water soluble initiator. Since initiator concentration greatly influences polymerization process, the first step is to determine the optimum concentration of initiator $\left(\mathrm{K}_{2} \mathrm{~S}_{2} \mathrm{O}_{8}\right)$. The reactions conditions and reactants concentrations are shown in Table 2.

From Figure 6, it is observed that, with increasing of initiator concentration, the apparent viscosity rises up until it reaches a maximum value at initiator concentration of $6.07 \times$ $10^{-3} \mathrm{molL}^{-1}$ so it is the optimum initiator concentration. On the other hand, if the concentration of initiator was too high,
TABLE 2: Reactions conditions with different initiator concentrations.

\begin{tabular}{|c|c|c|c|c|c|c|c|c|}
\hline Run & $\# A$ & $B$ & $C$ & $D$ & $E$ & $F$ & $G$ & $H$ \\
\hline 1 & & & $1.52 * 10^{-3}$ & & & & & 1460.81 \\
\hline 2 & & & $3.03 * 10^{-3}$ & & & & & 1510.72 \\
\hline 3 & 1.69 & $3.38 * 10^{-2}$ & $6.07 * 10^{-3}$ & $1.14 * 10^{-2}$ & 60 & 5.4 & 12 & 1908.07 \\
\hline 4 & & & $1.21 * 10^{-2}$ & & & & & 1733.39 \\
\hline 5 & & & $2.43 * 10^{-2}$ & & & & & 1485.76 \\
\hline
\end{tabular}

$A$ : monomer (acrylamide) concentration, $\mathrm{molL}^{-1}$. B: surfmer concentration, $\mathrm{molL}^{-1}$. C: initiator (KPS) concentration, $\mathrm{molL}^{-1} . D$ : cross-linker (DVS) concentration, $\mathrm{molL}^{-1}$. E: temperature, ${ }^{\circ} \mathrm{C}$. F: PH-value. G: reaction time, hours. $H$ : apparent viscosity, mPa.s.

the apparent viscosity decreased, and this can be attributed to the following.

By increasing of initiator concentration, the amount of free radical increased consequently, the probability of chain 
TABLE 3: Reactions conditions with different monomer concentrations.

\begin{tabular}{lcccccr}
\hline Run\# & $A$ & $B$ & $C$ & $D$ & $E$ & $F$ \\
\hline 1 & $4.22 * 10^{-1}$ & & & & & \\
2 & $8.44 * 10^{-1}$ & & & & & \\
3 & 1.69 & $3.38 * 10^{-2}$ & $6.07 * 10^{-3}$ & $1.14 * 10^{-2}$ & 60 & 5.4 \\
4 & 3.38 & & & & 1480.51 \\
5 & 6.75 & & & & 1908.07 \\
\hline
\end{tabular}

A: monomer (acrylamide) concentration, $\mathrm{molL}^{-1} . B$ : surfmer concentration, $\mathrm{molL}^{-1}$. C: initiator (KPS) concentration, $\mathrm{molL}^{-1}$. D: cross-linker (DVS) concentration, $\mathrm{molL}^{-1}$. E: temperature, ${ }^{\circ} \mathrm{C}$. F: PH-value. G: reaction time, hours. $H$ : apparent viscosity, $\mathrm{mPa} \cdot \mathrm{s}$.

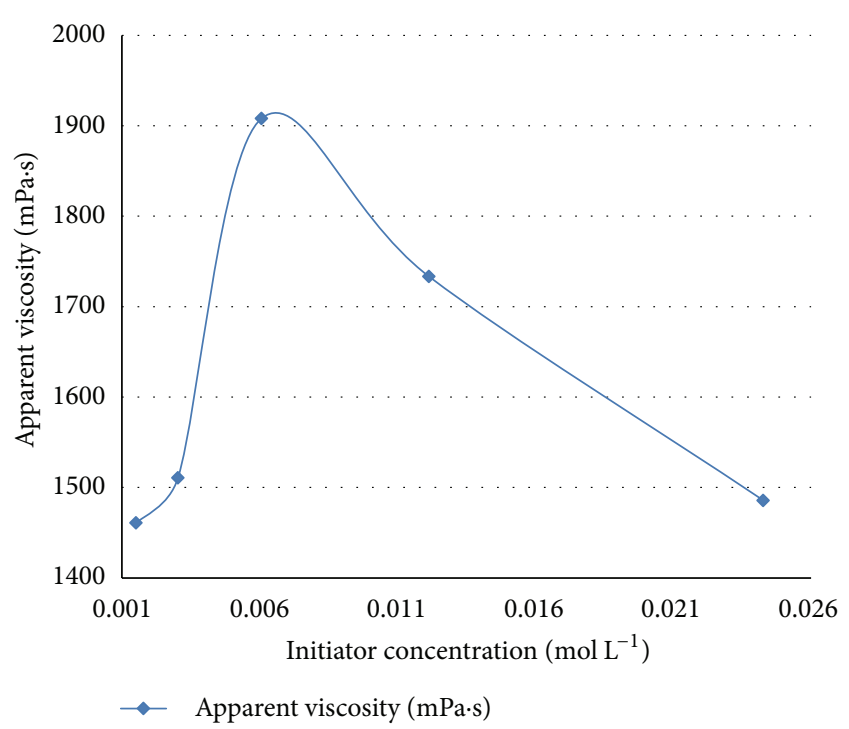

FIGURE 6: Effect of initiator concentration on apparent viscosity.

growth increased, and at the same time the molecular chain elongated, so apparent viscosity rose. If the concentration of initiators was too much, the free radical generated was too much and the propagation of chain transfer increased, so the probability of chain termination increased and the molecular chain was shorter, so viscosity decreases.

3.4.2. Effects of Acrylamide Monomer Concentration. Effect of acrylamide (AM) monomer concentration on apparent viscosity was investigated, where the reactions conditions and reactants concentrations are shown in Table 3. From Figure 7, it is observed that when the concentration of monomer was lower, the apparent viscosity of polymer was lower too. With the increase of monomer concentration, the apparent viscosity of polymer increases. The apparent viscosity of polymer was the maximum when the concentration of monomer was $1.69 \mathrm{molL}^{-1}$. After that, the apparent viscosity decreased, so it is the optimum monomer concentration.

This behavior can be explained on basis of the following; with the increases of monomer concentration, the concentration of propagating radical increases, the probability of chain growth increases at the same time, the molecular chain elongates, and the apparent viscosity rises. But if the concentration of monomers was too much, the probability of collision between monomer radicals becomes larger, so the

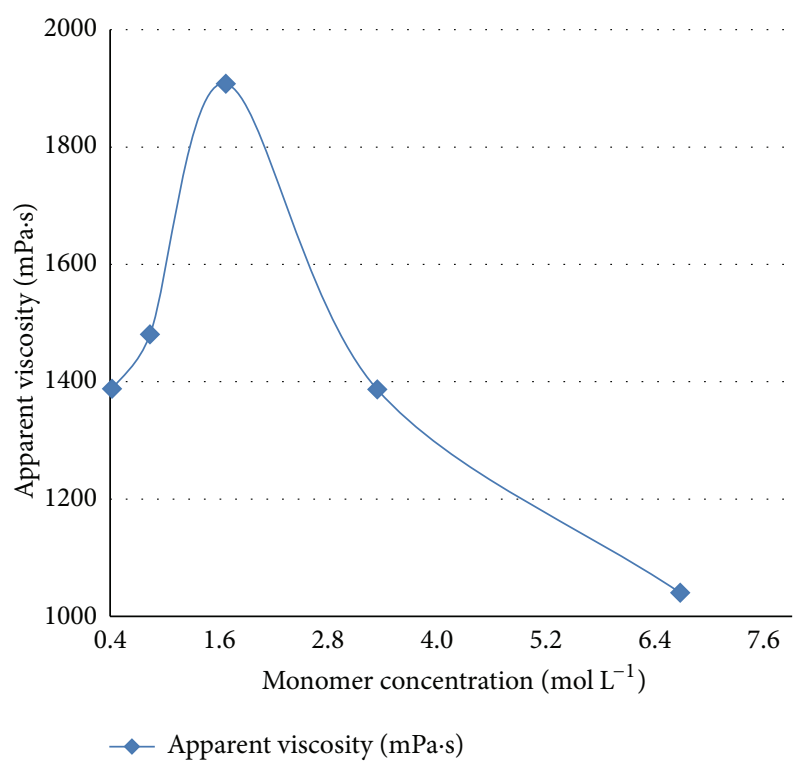

FIGURE 7: Effect of monomer concentration on apparent viscosity.

TABLE 4: Reactions conditions with different temperatures.

\begin{tabular}{|c|c|c|c|c|c|c|c|}
\hline Run & $\# A$ & $B$ & $C$ & $D$ & $E$ & $F \quad G$ & $H$ \\
\hline 1 & & & & & 40 & & 832.66 \\
\hline 2 & & & & & 50 & & 1755.42 \\
\hline 3 & 1.69 & $3.38 * 10^{-2}$ & $6.07 * 10^{-3}$ & $1.14 * 10^{-2}$ & 60 & 5.412 & 1908.07 \\
\hline 4 & & & & & 65 & & 1335.65 \\
\hline 5 & & & & & 70 & & 749.40 \\
\hline
\end{tabular}

A: monomer (acrylamide) concentration, molL $^{-1}$. B: surfmer concentration, $\mathrm{molL}^{-1}$. C: initiator (KPS) concentration, $\mathrm{molL}^{-1} . \mathrm{D}$ : cross-linker (DVS) concentration, molL ${ }^{-1}$. E: temperature, ${ }^{\circ} \mathrm{C}$. F: PH-value. G: reaction time, hours. $H$ : apparent viscosity, mPa.s.

probability of chain termination rises up and the molecular chain became shorter, resulting in lower viscosity values.

3.4.3. Effects of Reaction Temperature. Effect of reaction temperature on polymerization conditions was investigated, where the reactions conditions and reactants concentrations are shown in Table 4.

From Figure 8, it is observed that, with the increase of reaction temperature, the apparent viscosity increases until reaching a maximum value at $60^{\circ} \mathrm{C}$ and then decreases, so it is the optimum temperature. Because the constant of chain 


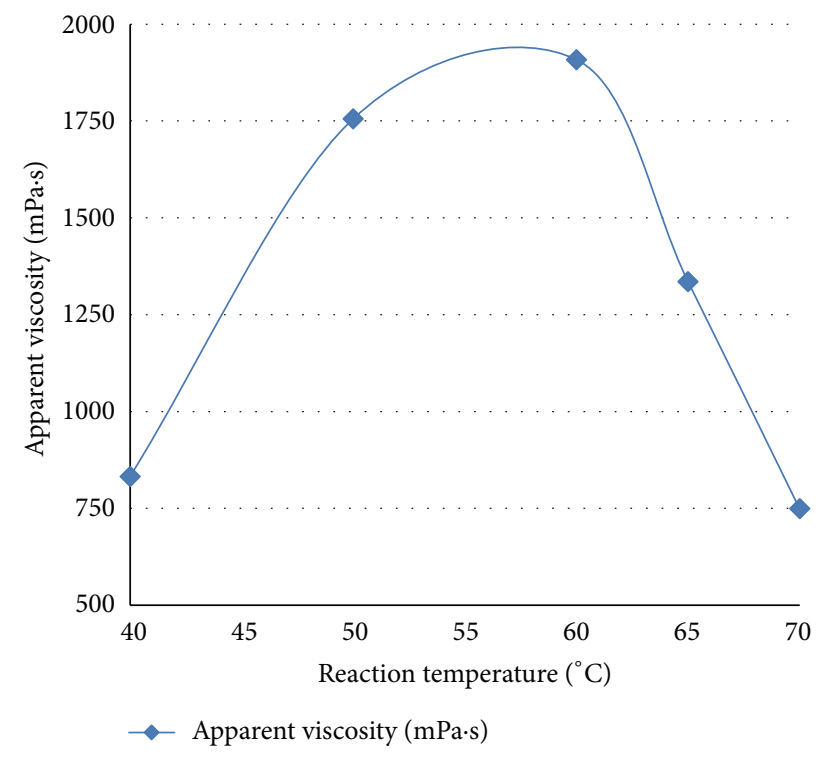

FIGURE 8: Effect of reaction temperature on apparent viscosity.

transfer and chain termination increased in higher temperature, these accelerated the velocity of polymerization up to a certain limit, and after that chain termination accelerated, so the apparent viscosity of polymers decreased. When the temperature was lower, the activity of monomer radical decreased, and the probability of collision between monomer radicals was lower too, so viscosity decreases. With the increase of the reaction temperature, the amount of free radical increased, the probability of chain growth increased at the same time, the molecular chain elongated, and apparent viscosity became larger. But if the reaction temperature was too high, the free radical generated was too much, the propagation of chain transfer increased, and the molecular chain became shorter. Also, it is assumed that at high temperatures the primary radicals undergo side reactions so their contribution to polymerization is suppressed.

3.4.4. Effects of Cross-Linker Concentration. Since introducing of sulfone group in backbone structure of polymer enhances ionic exchange capability, electric conductivity, and reduces precipitation with bivalent $\mathrm{Ca}^{2+}$ and $\mathrm{Mg}^{2+}$ ions $[39,40]$, it improves polymer resistance to harsh reservoir conditions during flooding process. As a result, it is favorable to select cross-linker containing sulfone group in its chemical structure. Effect of hydrophobic cross-linker concentration (divinyl sulfone (DVS)) moiety on polymerization conditions was investigated in relation to apparent viscosity, where the reactions conditions and reactants concentrations are shown in Table 5.

From Figure 9, it is observed that the apparent viscosity increases with the increase of cross-linker concentration. Because the divinyl sulfone cross-linker contains strong polar groups $(\mathrm{O}=\mathrm{S}=\mathrm{O})$, the copolymer obtained becomes more rigid with the increase of hydrophobic cross-linker concentration.
TABLE 5: Reactions conditions with different cross-linker concentrations.

\begin{tabular}{|c|c|c|c|c|c|c|c|}
\hline Run\# & $\# A$ & $B$ & $C$ & $D$ & $E$ & $F \quad G$ & $H$ \\
\hline 1 & & & & $2.84 * 10^{-3}$ & & & 1621.86 \\
\hline 2 & & & & $5.68 * 10^{-3}$ & & & 1717.26 \\
\hline 3 & 1.69 & $3.38 * 10^{-2}$ & $6.07 * 10^{-3}$ & $1.14 * 10^{-2}$ & 60 & 5.412 & 21908.07 \\
\hline 4 & & & & $2.27 * 10^{-2}$ & & & 1854.64 \\
\hline 5 & & & & $4.54 * 10^{-2}$ & & & 1761.91 \\
\hline
\end{tabular}

A: monomer (acrylamide) concentration, molL $^{-1} . B$ : surfmer concentration, $\mathrm{molL}^{-1}$. C: initiator (KPS) concentration, $\mathrm{molL}^{-1} . D$ : cross-linker (DVS) concentration, $\mathrm{molL}^{-1}$. E: temperature, ${ }^{\circ} \mathrm{C} . \mathrm{F}$ : PH-value. G: reaction time, hours. $H$ : apparent viscosity, mPa.s.

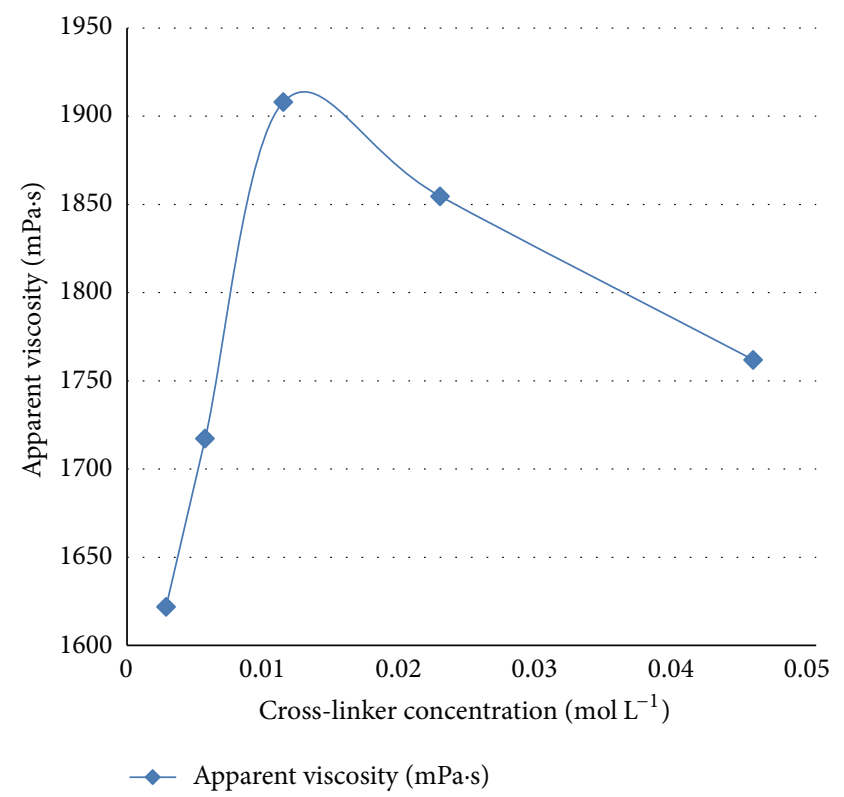

FIGURE 9: Effect of cross-linker concentration on apparent viscosity.

When cross-linker concentration was too much, the polarity of copolymer was too strong, and the produced composite becomes so rigid and insoluble in aqueous solution, so viscosity decreases. The experimental demonstrated crosslinker concentration at $1.14 * 10^{-2} \mathrm{molL}^{-1}$ was the optimum one.

3.4.5. Effects of Surfmer Concentration. Based on previous experiments determined above, concentration of reactants was adjusted at optimum where effect of surfmer concentration was investigated in relation to apparent viscosity. The reactions conditions and reactants concentrations are shown in Table 6.

From Figure 10, it is observed that the apparent viscosity decreases by increasing surfmer concentration. This can be attributed to the following: the higher the surfmer content, the higher the monomer swollen micelles which are the loci of polymerization, the smaller the hydrophobe number per micelle, and the shorter the sequence length of the hydrophobic segments in the macromolecular backbone, 
TABLE 6: Reactions conditions with different surfmer concentrations.

\begin{tabular}{|c|c|c|c|c|c|c|c|c|}
\hline Run\# & & $B$ & $C$ & $D$ & $E$ & $F G$ & $G$ & $H$ \\
\hline 1 & & $8.44 * 10^{-3}$ & & & & & & 2119.87 \\
\hline 2 & & $1.69 * 10^{-2}$ & & & & & & 1927.15 \\
\hline 3 & 1.69 & $3.38 * 10^{-2}$ & $6.07 * 10^{-3}$ & $1.14 * 10^{-2}$ & 60 & 5.412 & 121 & 1908.07 \\
\hline 4 & & $6.75 * 10^{-2}$ & & & & & & 1526.46 \\
\hline 5 & & $1.35 * 10^{-1}$ & & & & & & 954.04 \\
\hline
\end{tabular}

$A$ : monomer (acrylamide) concentration, $\mathrm{molL}^{-1}$. B: surfmer concentration, molL ${ }^{-1}$. C: initiator (KPS) concentration, $\mathrm{molL}^{-1}$. D: cross-linker (DVS) concentration, $\mathrm{molL}^{-1}$. E: temperature, ${ }^{\circ} \mathrm{C}$. F: PH-value. G: reaction time, hours. $H$ : apparent viscosity, $\mathrm{mPa} \cdot \mathrm{s}$.

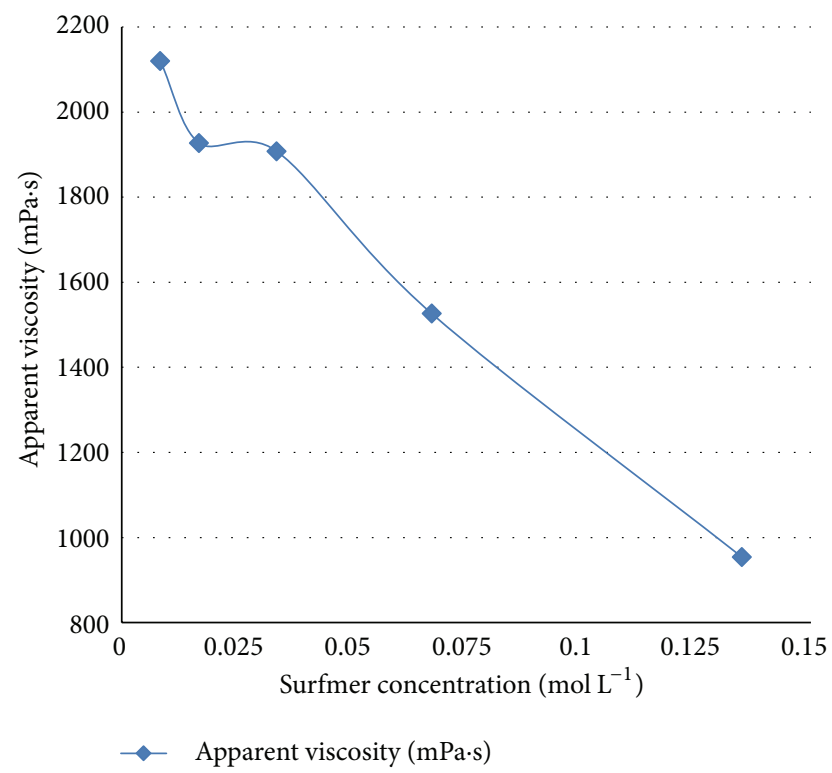

FIGURE 10: Effect of surfmer concentration on apparent viscosity.

which reduces the tendency for intermolecular association, so solution viscosity decreases [41].

Number of hydrophobic monomers per micelle $\left(N_{H}\right)$ can be calculated by $[42,43]$

$$
N_{H}=\frac{\left[M_{H}\right]}{\left(\left[X_{\text {surf }}\right]-C m c\right)} N_{\text {agg }}
$$

where $M_{H}$ is initial molar concentration of hydrophobic monomer in the feed, molL $^{-1} ; X_{\text {surf }}$ is molar surfmer concentration, $\mathrm{molL}^{-1}$; $\mathrm{Cmc}$ is critical micelle concentration, $\mathrm{molL}^{-1} ; N_{\mathrm{agg}}$ is surfmers aggregation number (mean number of hydrophobes per aggregate reflecting the amount of aggregating polymer chains that participate in hydrophobic domain formation) [44]. In this study, the Cmc of surfmer at $60^{\circ} \mathrm{C}$ was found to be $0.001485 \mathrm{molL}^{-1}$ and an aggregation number $N_{\mathrm{agg}}=15$ was assumed for surfmer at the polymerization temperature of $60^{\circ} \mathrm{C}[45,46]$. The values of hydrophobic monomers per micelle $\left(N_{H}\right)$, as a function of surfmer concentration, are reported in Table 7.

According to previous data results, it is obvious that surfmer concentration $8.44 * 10^{-3} \mathrm{molL}^{-1}$ gives the highest
TABLE 7: Values of $N_{H}$ as a function of surfmer concentration.

\begin{tabular}{lc}
\hline Surfmer concentration, molL $^{-1}$ & $\begin{array}{c}\text { Number of hydrophobes } \\
\text { per micelle }\left(N_{H}\right)\end{array}$ \\
\hline $8.44 * 10^{-3}$ & 31.16 \\
$1.69 * 10^{-2}$ & 12.25 \\
$3.38 * 10^{-2}$ & 5.53 \\
$6.75 * 10^{-2}$ & 2.64 \\
$1.35 * 10^{-1}$ & 1.29 \\
\hline
\end{tabular}

TABLE 8: The optimum polymerization conditions in accordance with single-factor experiments.

\begin{tabular}{lccccccc}
\hline$A$ & $B$ & $C$ & $D$ & $E$ & $F$ & $G$ & $H$ \\
\hline $\mathbf{1 . 6 9}$ & $3.38 * 10^{-2}$ & $6.07 * 10^{-3}$ & $1.14 * 10^{-2}$ & 60 & 5.4 & 12 & 1908.07 \\
\hline$A .12$
\end{tabular}

A: monomer (acrylamide) concentration, $\mathrm{molL}^{-1}$. B: surfmer concentration, molL ${ }^{-1}$. C: initiator (KPS) concentration, $\mathrm{molL}^{-1} . D$ : cross-linker (DVS) concentration, $\mathrm{molL}^{-1}$. E: temperature, ${ }^{\circ} \mathrm{C}$. F: PH-value. G: reaction time, hours. $H$ : apparent viscosity, mPa.s.

$N_{H}$ and viscosity values, but we found that the optimum surfmer concentration which achieves high latex stability is $3.38 * 10^{-2} \mathrm{molL}^{-1}$ which is 22.7 -fold its Cmc. Moreover, at lower surfmers concentration and higher $N_{H}$ values, the solubility of hydrophobically associated copolymers in water was found to be nil as it becomes only soluble in high polar solvents like formamide [47] due to increasing of hydrophobic groups in micelle, so hydrophobe block lengthen and association of hydrophobic groups become stronger resulting in poor solubility [48], so surfmer concentration of $3.38 *$ $10^{-2} \mathrm{molL}^{-1}$ was found to be the optimum concentration during the course of polymerization process. From the aforementioned single-factor experiments, we can deduce that the optimum polymerization conditions can be summarized as shown in Table 8.

3.4.6. Reaction Time. Rate of monomer conversion was estimated through gravimetric precipitation technique. A definite weight of as-synthesized copolymer was withdrawn and precipitated in acetone at interval time of $(2,4,6,8,10$, 12 , and 14 hours) and reweighted after vacuum-drying. The converted monomer was calculated by subtracting weight after drying from theoretical weight of monomer in definite solution. All titration experiments were repeated 3 times for accuracy. Experimental results are summarized as shown in Table 9 and Figure 11.

It is obvious that maximum conversion reaches 92 and 95\% in case of HAPAM and HAPAM- $\mathrm{SiO}_{2}$, respectively, after 12 hours. As a result, optimum time of polymerization reaction through this study was adjusted at 12 hours to assure that monomer conversion occurs completely.

3.5. Orthogonal Experiments [33]. In order to determine the effects of initiator, monomer, cross-linker, and surfmer concentrations and reaction temperature on apparent viscosity of the product comprehensively, orthogonal experiments were 
TABLE 9: Monomer conversion rate with time.

\begin{tabular}{lcc}
\hline Time, hours & \multicolumn{2}{c}{ Monomer conversion \% } \\
& HAPAM & HAPAM-SiO \\
\hline 0 & 0 & 0 \\
2 & 35 & 40 \\
4 & 63 & 70 \\
6 & 82 & 83.5 \\
8 & 91 & 94 \\
10 & 91.5 & 95 \\
12 & 92 & 95 \\
14 & 92.2 & 95 \\
\hline
\end{tabular}

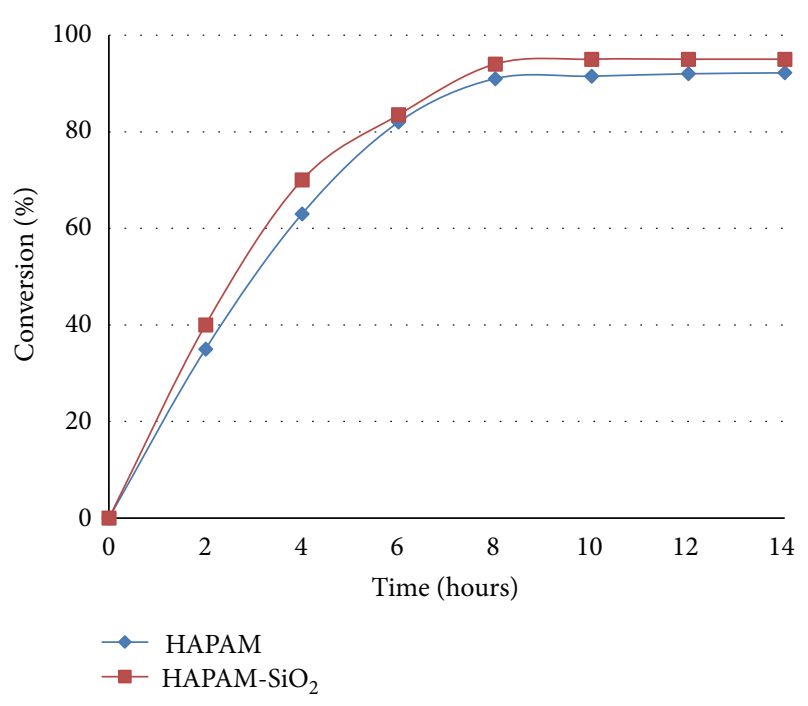

FIGURE 11: Monomer conversion with time.

TABLE 10: Factors and levels.

\begin{tabular}{lccccc}
\hline Levels & $A$ & $B$ & $C$ & $D$ & $E$ \\
\hline 1 & $1.52 * 10^{-3}$ & $4.22 * 10^{-1}$ & 40 & $2.84 * 10^{-3}$ & $8.44 * 10^{-3}$ \\
2 & $3.03 * 10^{-3}$ & $8.44 * 10^{-1}$ & 50 & $5.68 * 10^{-3}$ & $1.69 * 10^{-2}$ \\
3 & $6.07 * 10^{-3}$ & 1.69 & 60 & $1.14 * 10^{-2}$ & $3.38 * 10^{-2}$ \\
4 & $1.21 * 10^{-2}$ & 3.38 & 65 & $2.27 * 10^{-2}$ & $6.75 * 10^{-2}$ \\
\hline
\end{tabular}

$A$ : initiator (KPS) concentration, olL $^{-1}$. B: monomer (acrylamide) concentration, $\mathrm{molL}^{-1}$. C: temperature, ${ }^{\circ} \mathrm{C}$. D: cross-linker (DVS) concentration, molL ${ }^{-1}$. E: surfmer concentration, $\mathrm{molL}^{-1}$.

done. Based on the single-factor experiment, the factors and levels, results of synthesis, and range analysis with apparent viscosity are shown in Tables $10-12$, respectively.

Statistic parameters were defined according to the following equations:

$$
\begin{aligned}
L_{i} & =\sum I_{i}, \\
K_{i} & =\frac{L_{i}}{4}, \\
R & =\max \left(K_{i}\right)-\min \left(K_{i}\right),
\end{aligned}
$$

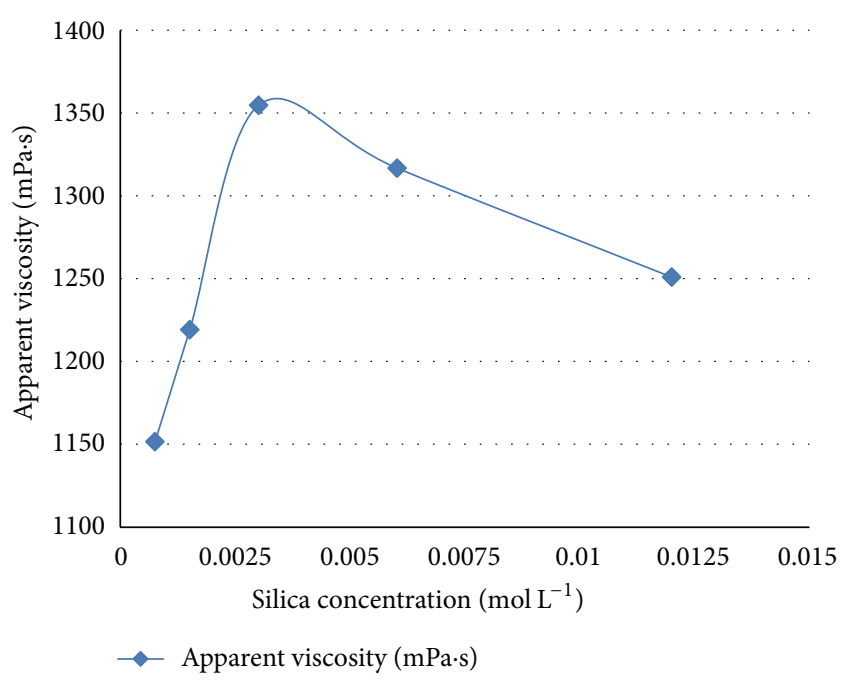

FIGURE 12: Effect of silica concentration on apparent viscosity.

where $i$ is the experimental levels, $i=1,2,3,4$, and $I$ is experimental results, such as apparent viscosity.

From Table 12, it can be seen that $R_{D}>R_{C}>R_{B}>$ $R_{E}>R_{A}$. It demonstrated that the apparent viscosity was most affected by cross-linker concentration followed by reaction temperature, monomers concentration, surfmer concentration, and initiators concentration. From orthogonal experiments, it is observed that the optimum combination was $A_{3} B_{3} C_{3} D_{3} E_{3}$, which is compatible with the results obtained from single-factor experiments as illustrated in Table 8 previously.

3.6. Effect of Silica Load. After determination of optimum polymerization conditions through single-factor and orthogonal experiments, effect of silica load (3-aminopropyl)triethoxysilane on polymerization conditions was investigated in relation to apparent viscosity, where the reactions conditions and reactants concentrations are shown in Table 13.

From Figure 12, it is observed that the apparent viscosity increases with the increase of silica load till certain concentration $\left(0.003 \mathrm{molL}^{-1}\right)$ and then decreases, so it is the optimum concentration. This may be attributed to the following: by increasing of silica concentration till certain limit, reaction initiation increases, so the probability of chain growth increased, resulting in viscosity increase. When silica concentration becomes too high, the possibility of reaction termination increases; moreover cross-linking degree decreases by grafting of silica nanoparticles, so intermolecular hydrophobic associations and gel effect decrease resulting in viscosity decrease.

Also it is observed that viscosity of HAPAM- $\mathrm{SiO}_{2}$ nanocomposite is lower than that of HAPAM. This resorted to part of divinyl sulfone cross-linker consumed with (3-aminopropyl)triethoxysilane during Aza-Michael addition reaction, so chains association becomes less rigid resulting in lower viscosity values according to Scheme 1 . 
TABLE 11: Results of synthesis.

\begin{tabular}{|c|c|c|c|c|c|c|c|}
\hline \multirow{2}{*}{ Number } & \multirow{2}{*}{ Combination of factors and levels } & \multicolumn{6}{|c|}{ Factors } \\
\hline & & $A$ & $B$ & C & $D$ & $E$ & $F$ \\
\hline 1 & $A_{1} B_{1} C_{1} D_{1} E_{1}$ & $1.52 * 10^{-3}$ & $4.22 * 10^{-1}$ & 40 & $2.84 * 10^{-3}$ & $8.44 * 10^{-3}$ & 1484.59 \\
\hline 2 & $A_{1} B_{2} C_{2} D_{2} E_{2}$ & $1.52 * 10$ & $8.44 * 10^{-1}$ & 50 & $5.68 * 10^{-3}$ & $1.69 * 10^{-2}$ & 1668.23 \\
\hline 3 & $A_{1} B_{3} C_{3} D_{3} E_{3}$ & $1.52 * 10$ & 1.69 & 60 & $1.14 * 10^{-2}$ & $3.38 * 10^{-2}$ & 1818.62 \\
\hline 4 & $A_{1} B_{4} C_{4} D_{4} E_{4}$ & $1.52 * 10$ & 3.38 & 65 & $2.27 * 10^{-2}$ & $6.75 * 10^{-2}$ & 1512.85 \\
\hline 5 & $A_{2} B_{1} C_{2} D_{3} E_{4}$ & $3.03 * 10^{-3}$ & $4.22 * 10^{-1}$ & 50 & $1.14 * 10^{-2}$ & $6.75 * 10^{-2}$ & 1617.69 \\
\hline 6 & $A_{2} B_{2} C_{3} D_{4} E_{3}$ & $3.03 * 10^{-3}$ & $8.44 * 10^{-1}$ & 60 & $2.27 * 10^{-2}$ & $3.38 * 10^{-2}$ & 1732.40 \\
\hline 7 & $A_{2} B_{3} C_{4} D_{1} E_{2}$ & $3.03 * 10^{-3}$ & 1.69 & 65 & $2.84 * 10^{-3}$ & $1.69 * 10^{-2}$ & 1487.08 \\
\hline 8 & $A_{2} B_{4} C_{1} D_{2} E_{1}$ & $3.03 * 10^{-3}$ & 3.38 & 40 & $5.68 * 10^{-3}$ & $8.44 * 10^{-3}$ & 1513.44 \\
\hline 9 & $A_{2} B_{2} C_{2} D_{2} E_{2}$ & $3.03 * 10^{-3}$ & $8.44 * 10^{-1}$ & 50 & $5.68 * 10^{-3}$ & $1.69 * 10^{-2}$ & 1678.21 \\
\hline 10 & $A_{3} B_{1} C_{3} D_{2} E_{4}$ & $6.07 * 10^{-3}$ & $4.22 * 10^{-1}$ & 60 & $5.68 * 10^{-3}$ & $6.75 * 10^{-2}$ & 1689.53 \\
\hline 11 & $A_{3} B_{2} C_{2} D_{4} E_{3}$ & $6.07 * 10^{-3}$ & $8.44 * 10^{-1}$ & 50 & $2.27 * 10^{-2}$ & $3.38 * 10^{-2}$ & 1781.34 \\
\hline 12 & $A_{3} B_{3} C_{4} D_{3} E_{2}$ & $6.07 * 10^{-3}$ & 1.69 & 65 & $1.14 * 10^{-2}$ & $1.69 * 10^{-2}$ & 1797.40 \\
\hline 13 & $A_{3} B_{4} C_{1} D_{1} E_{1}$ & $6.07 * 10^{-3}$ & 3.38 & 40 & $2.84 * 10^{-3}$ & $8.44 * 10^{-3}$ & 1573.83 \\
\hline 14 & $A_{3} B_{3} C_{3} D_{3} E_{3}$ & $6.07 * 10^{-3}$ & 1.69 & 60 & $1.14 * 10^{-2}$ & $3.38 * 10^{-2}$ & 1908.07 \\
\hline 15 & $A_{4} B_{1} C_{4} D_{1} E_{3}$ & $1.21 * 10^{-2}$ & $4.22 * 10^{-1}$ & 65 & $2.84 * 10^{-3}$ & $3.38 * 10^{-2}$ & 1597.35 \\
\hline 16 & $A_{4} B_{2} C_{3} D_{2} E_{4}$ & $1.21 * 10^{-2}$ & $8.44 * 10^{-1}$ & 60 & $5.68 * 10^{-3}$ & $6.75 * 10^{-2}$ & 1673.14 \\
\hline 17 & $A_{4} B_{3} C_{2} D_{3} E_{1}$ & $1.21 * 10^{-2}$ & 1.69 & 50 & $1.14 * 10^{-2}$ & $8.44 * 10^{-3}$ & 1884.96 \\
\hline 18 & $A_{4} B_{4} C_{1} D_{4} E_{2}$ & $1.21 * 10^{-2}$ & 3.38 & 40 & $2.27 * 10^{-2}$ & $1.69 * 10^{-2}$ & 1546.91 \\
\hline 19 & $A_{4} B_{4} C_{4} D_{4} E_{4}$ & $1.21 * 10^{-2}$ & 3.38 & 65 & $2.27 * 10^{-2}$ & $6.75 * 10^{-2}$ & 1567.37 \\
\hline
\end{tabular}

$A$ : initiator (KPS) concentration, molL $^{-1}$. B: monomer (acrylamide) concentration, molL ${ }^{-1}$. C: temperature, ${ }^{\circ} \mathrm{C} . D$ : cross-linker (DVS) concentration, molL ${ }^{-1}$. E: surfmer concentration, $\mathrm{molL}^{-1}$. F: apparent viscosity, mPa.s.

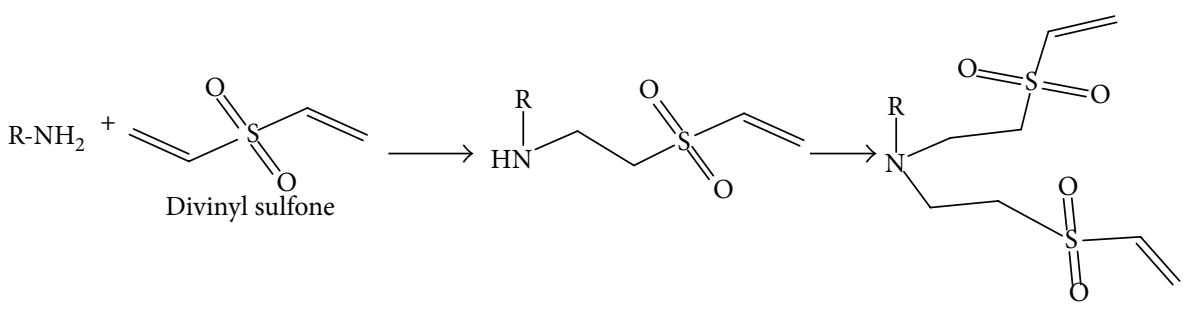

SCHEME 1

TABLE 12: Range analysis with apparent viscosity.

\begin{tabular}{lccccc}
\hline & $A$ & $B$ & $C$ & $D$ & $E$ \\
\hline$L_{1}$ & 6484.30 & 6389.15 & 6118.78 & 6142.86 & 6456.84 \\
$L_{2}$ & 8028.83 & 6855.11 & 8630.44 & 8222.55 & 8177.84 \\
$L_{3}$ & 8750.17 & 8896.14 & 8821.75 & 9026.74 & 8837.78 \\
$L_{4}$ & 8269.73 & 7714.41 & 7962.06 & 8140.88 & 8060.58 \\
$K_{1}$ & 1621.07 & 1597.29 & 1529.70 & 1535.71 & 1614.21 \\
$K_{2}$ & 2007.21 & 1713.78 & 2157.61 & 2055.64 & 2044.46 \\
$K_{3}$ & 2187.54 & 2224.03 & 2205.44 & 2256.69 & 2209.45 \\
$K_{4}$ & 2067.43 & 1928.60 & 1990.51 & 2035.22 & 2015.14 \\
$R$ & $\mathbf{5 6 6 . 4 7}$ & $\mathbf{6 2 6 . 7 5}$ & $\mathbf{6 7 5 . 7 4}$ & $\mathbf{7 2 0 . 9 7}$ & $\mathbf{5 9 5 . 2 4}$ \\
\hline
\end{tabular}

A: initiator (KPS) concentration, molL $^{-1}$. B: monomer (acrylamide) concentration, $\mathrm{molL}^{-1}$. C: temperature, ${ }^{\circ} \mathrm{C} . \mathrm{D}$ : cross-linker (DVS) concentration, $\mathrm{molL}^{-1}$. E: surfmer concentration, $\mathrm{molL}^{-1}$.

\section{Estimation of Total Oil Recovery Factor by Copolymers Flooding}

Flooding experiments were carried out on one-dimensional sandstone packed model at simulated reservoir conditions. The recovery factor was calculated by two methods, using either a secondary oil displacement procedure or means of a tertiary oil displacement technique, overall comprising two steps [49]. The first step, corresponding to the secondary recovery method, involves the injection of brine into the sand pack, after saturating of packed model with crude oil. At this point, a certain amount of oil is recovered and another one remains in the sand pack. The experimental data results are summarized in Table 14 and Figure 13. The brine only pushes away the oil found in the sand pack, under high interfacial 
TABLE 13: Reactions conditions with different silica concentrations.

\begin{tabular}{lccccrrr}
\hline Run\# & $A$ & $B$ & $C$ & $D$ & $E$ & $G$ & $H$ \\
\hline 1 & & & & $7.53 * 10^{-4}$ & & \\
2 & & & & $1.51 * 10^{-3}$ & & \\
3 & 1.69 & $3.38 * 10^{-2}$ & $6.07 * 10^{-3}$ & $1.14 * 10^{-2}$ & $3.01 * 10^{-3}$ & 60 & 5.52 \\
4 & & & & $6.02 * 10^{-3}$ & 1219.26 \\
5 & & & $1.20 * 10^{-2}$ & 1354.73 \\
\hline
\end{tabular}

A: monomer (acrylamide) concentration, $\mathrm{molL}^{-1} . B$ : surfmer concentration, $\mathrm{molL}^{-1}$. C: initiator (KPS) concentration, $\mathrm{molL}^{-1}$. D: cross-linker (DVS) concentration, $\mathrm{molL}^{-1}$. E: silica concentration, $\mathrm{molL}^{-1}$. F: temperature, ${ }^{\circ} \mathrm{C}$. G; PH-value. $H$ : reaction time, hours. I: apparent viscosity, mPa.s.

TABLE 14: Secondary and tertiary recovery factors during flooding process.

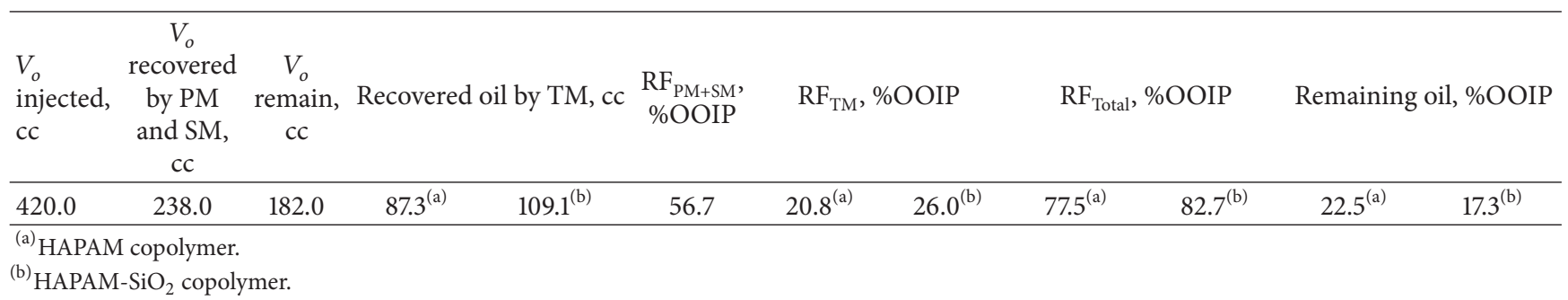

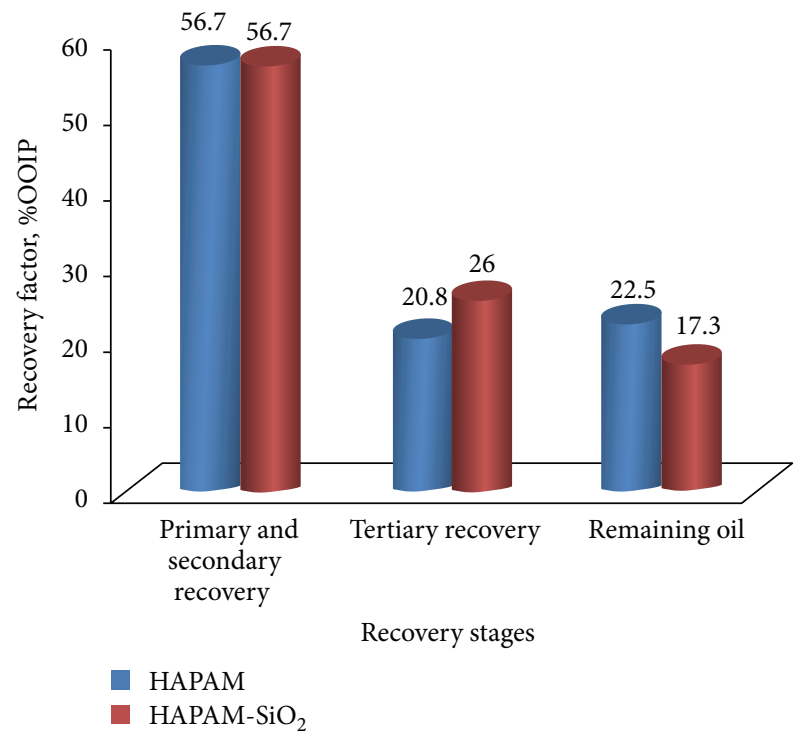

FIGURE 13: Recovery factor related to \%OOIP.

tensions and lacking any chemical interaction. The amount recovered is calculated via a mass balance:

Volume of oil remaining in the sand pack

$$
\text { = injected oil volume }- \text { expelled oil volume. }
$$

The second step is performed with the objective of recovering any amount of oil still stored in the sand pack, which corresponds to implementation of a tertiary recovery method, whereby copolymer solutions (HAPAM or HAPAM$\mathrm{SiO}_{2}$ ) are injected during flooding process. These solutions act to decrease mobility ratio and so improve sweeping efficiency and reduce interfacial tensions between the contacting fluids. As a result, the volume of recovered oil increases. The recovery factor relative to original oil in place (OOIP) is obtained by summing up the oil volume $\left(V_{o}\right)$ recovered in each step (secondary and tertiary oil displacement process) and is expressed in percentage (\%):

$$
\mathrm{RF}_{\text {Total }}=\mathrm{RF}_{\mathrm{PM}+\mathrm{SM}}+\mathrm{RF}_{\mathrm{TM}} \text {, }
$$

where $\mathrm{RF}_{\text {Total }}$ is total recovery factor $(\%), \mathrm{RF}_{\mathrm{PM}+\mathrm{SM}}$ is recovery factor obtained by primary and secondary methods (\%), and $\mathrm{RF}_{\mathrm{TM}}$ is recovery factor obtained by tertiary method (\%).

It is observed that recovery factor reaches 20.8 and $26 \%$ OOIP in case of HAPAM and HAPAM-SiO 2 copolymers, respectively, which indicate that the novel composites are promised EOR candidates.

\section{Conclusion}

The effects of acrylamide monomer, surfmer (4-Dodecylbenzenesulfonate-1-vinylimidazol-3-ium), divinyl sulfone as a hydrophobic cross-linker moiety, and potassium persulfate initiator concentrations as well as reaction temperature on apparent viscosity of polymerized hydrophobically associated polyacrylamide (HAPAM) copolymers were evaluated using single-factor and orthogonal experiments. Moreover, effect of silica concentration on apparent viscosity of HAPAM-SiO nanocomposite was also investigated. Flooding experiments through one-dimensional model indicate positive results for application of such polymers in enhanced oil recovery. As an ongoing research, the authors try to increase efficiency of these copolymers in order to decrease remaining oil percentage.

\section{Conflict of Interests}

The authors declare that there is no conflict of interests regarding the publication of this paper. 


\section{Acknowledgment}

The authors wish to thank the Science \& Technology Development Fund (STDF) of Egypt for financial support.

\section{References}

[1] R. Tabary and B. Bazin, "Advances in chemical flooding," in Proceedings of the IFP-OAPEC Joint Seminar; Improved Oil recovery (IOR) Techniques and Their Role in Boosting the Recovery Factor, Rueil-Malmaison, France, June 2007.

[2] US Department of Energy, 2008, http://www.fossil.energy.gov/ programs/oilgas/eor/index.html.

[3] S. M. Farouq-Ali and C. D. Stahl, "Increased oil recovery by improved water flooding," Earth and Mineral Sciences, vol. 39, no. 4, pp. 25-28, 1970.

[4] S. Thomas, J. R. Scoular, B. Verkoczy, and S. M. F. Ali, "Chemical methods for heavy oil recovery," Journal of Canadian Petroleum Technology, vol. 40, no. 3, pp. 56-61, 2001.

[5] G. Bastiat, B. Grassl, and J. François, "Study of sodium dodecyl sulfate/poly(propylene oxide) methacrylate mixed micelles for the synthesis of thermo-associative polymers by micellar polymerization," Polymer International, vol. 51, no. 10, pp. 958-965, 2002.

[6] Y. Feng, L. Billon, B. Grassl, G. Bastiat, O. Borisov, and J. François, "Hydrophobically associating polyacrylamides and their partially hydrolyzed derivatives prepared by post-modification. 2. Properties of non-hydrolyzed polymers in pure water and brine," Polymer, vol. 46, no. 22, pp. 9283-9295, 2005.

[7] Y. Zhao, J. Zhou, X. Xu et al., "Synthesis and characterization of a series of modified polyacrylamide," Colloid and Polymer Science, vol. 287, no. 2, pp. 237-241, 2009.

[8] T. T. Jiang, J. Lu, H. Y. Wang, B. H. Wang, H. J. Han, and H. J. Wu, "Analysis on toxic and hazardous substances of polymer surfactants used in oilfields," Advanced Materials Research, vol. 805-806, pp. 1344-1347, 2013.

[9] Y. A. Shashkina, Y. D. Zaroslov, V. A. Smirnov et al., "Hydrophobic aggregation in aqueous solutions of hydrophobically modified polyacrylamide in the vicinity of overlap concentration," Polymer, vol. 44, no. 8, pp. 2289-2293, 2003.

[10] M. Camail, A. Margaillan, I. Martin, A. L. Papailhou, and J. L. Vernet, "Synthesis of $N$-alkyl- and $N$-arylalkylacrylamides and micellar copolymerization with acrylamide," European Polymer Journal, vol. 36, no. 9, pp. 1853-1863, 2000.

[11] S. Vossoughi and C. S. Buller, "Permeability modification by insitu gelation with a newly discovered biopolymer," SPE Reservoir Engineering, vol. 6, no. 4, 1991.

[12] E. J. Manrique, V. E. Muci, and E. M. Gurfinkel, "EOR field experiences in carbonate reservoirs in the United States," SPE Reservoir Evaluation \& Engineering, vol. 10, no. 6, 2007.

[13] M. K. Dabbous, "Displacement of polymers in waterflooded porous media and its effect on subsequent micellar flood," Society of Petroleum Engineers Journal, vol. 17, no. 5, SPE 6203, p. 358, 1977.

[14] J. R. Platt and L. James, "Poly-(alpha-alkoxy) acrylamide and poly-(alpha-alkoxy) acrylamide complexes," CA 1153497 Al Patent, 1981.

[15] W. D. Hunter, "Process for secondary recovery," US Patent no. 4,297,226, 1981

[16] R. Cao, L. Cheng, and P. Lian, "Flow behavior of viscoelastic polymer solution in porous media," Journal of Dispersion Science and Technology, vol. 36, no. 1, pp. 41-50, 2015.
[17] A. Murduchowitz, "Secondary recovery process," US Patent, No. 4, 323,463, 1982.

[18] M. Morvan, P. Moreau, R. Tabary, and B. Bazin, "Desorbants for enhanced oil recovery," Patent WO 2013110774 A1, 2013.

[19] C. L. McCormick, W.-M. Wan, P. D. Pickett, and D. A. Savin, "Structurally controlled 'polysoaps' via RAFT copolymerization of AMPS and n-dodecyl acrylamide for environmental remediation," Polymer Chemistry, vol. 5, no. 3, pp. 819-827, 2014.

[20] Y. Du and L. Guan, "Field-scale polymer flooding: lessons learnt and experiences gained during past 40 years," in Proceedings of the SPE International Petroleum Conference, SPE 91787, Puebla, Mexico, 2004.

[21] W. Zou, J. Peng, Y. Yang, L. Zhang, B. Liao, and F. Xiao, "Effect of nano- $\mathrm{SiO}_{2}$ on the performance of poly(MMA/BA/MAA)/EP," Materials Letters, vol. 61, no. 3, pp. 725-729, 2007.

[22] A. R. Mahdavian, M. Ashjari, and A. B. Makoo, "Preparation of poly (styrene-methyl methacrylate) $/ \mathrm{SiO}_{2}$ composite nanoparticles via emulsion polymerization. An investigation into the compatiblization," European Polymer Journal, vol. 43, no. 2, pp. 336-344, 2007.

[23] K. Yang-Chuan, W. Guang-Yao, and W. Yi, "Preparation, morphology and properties of nanocomposites of polyacrylamide copolymers with monodisperse silica," European Polymer Journal, vol. 44, no. 8, pp. 2448-2457, 2008.

[24] A. Flaaten, Q. P. Nguyen, G. A. Pope, and J. Zhang, "A systematic laboratory approach to low-cost, high-performance chemical flooding," in Proceedings of the SPE/DOE Symposium on Improved Oil Recovery, SPE 73803, 2, 915, 2008.

[25] T. Zhang, M. Roberts, S. L. Bryant, and C. Huh, "Foams and emulsions stabilized with nanoparticles for potential conformance control applications," in Proceedings of the SPE International Symposium on Oilfield Chemistry, SPE-121744-MS, The Woodlands, Tex, USA, April 2009.

[26] B. Ju and T. Fan, "Experimental study and mathematical model of nanoparticle transport in porous media," Powder Technology, vol. 192, no. 2, pp. 195-202, 2009.

[27] A. Z. Abidin, T. Puspasari, and W. A. Nugroho, "Polymers for enhanced oil recovery technology," Procedia Chemistry, vol. 4, pp. 11-16, 2012.

[28] B. Gao, H. Guo, J. Wang, and Y. Zhang, "Preparation of hydrophobic association polyacrylamide in a new micellar copolymerization system and its hydrophobically associative property," Macromolecules, vol. 41, no. 8, pp. 2890-2897, 2008.

[29] P. Reb, K. Margarit-Puri, M. Klapper, and K. Müllen, "Polymerizable and non polymerizable isophthalic acid derivatives as surfactants in emulsion polymerization," Macromolecules, vol. 33, no. 21, pp. 7718-7723, 2000.

[30] A. Guyot, "Advances in reactive surfactants," Advances in Colloid and Interface Science, vol. 108-109, pp. 3-22, 2004.

[31] C. J. Zou, P. W. Zhao, Y. Lei et al., "Preparation and performance of a novel water-soluble cationic polymer containing $\beta$ cyclodextrin," Chemical Engineering \& Technology, vol. 34, no. 11, pp. 1820-1826, 2011.

[32] Z. Ye, M. Feng, S. Gou, M. Liu, Z. Huang, and T. Liu, "Hydrophobically associating acrylamide-based copolymer for chemically enhanced oil recovery," Journal of Applied Polymer Science, vol. 130, no. 4, pp. 2901-2911, 2013.

[33] W. Sun, G. Zhang, L. Pan, H. Li, and A. Shi, "Synthesis, characterization, and flocculation properties of branched cationic polyacrylamide," International Journal of Polymer Science, vol. 2013, Article ID 397027, 10 pages, 2013. 
[34] T. Yuan, Q.-F. Luo, J.-Y. Hu, S.-L. Ong, and W.-J. Ng, "A study on arsenic removal from household drinking water," Journal of Environmental Science and Health, vol. 38, no. 9, pp. 1731-1744, 2003.

[35] A. N. El-hoshoudy, S. E. M. Desouky, M. Y. El-kady, A. M. Al-sabagh, M. H. Betiha, and S. Mahmoud, "Evaluation of solution and rheological properties for hydrophobically associated polyacrylamide copolymer as a promised enhanced oil recovery candidate," International Journal of Engineering Sciences \& Management Research, vol. 7, no. 2, 2015.

[36] Y. Z. Zhao, J. Z. Zhou, X. H. Xu et al., "Synthesis and characterization of a series of modified polyacrylamide," Colloid and Polymer Science, vol. 287, no. 2, pp. 237-241, 2009.

[37] S. Hayakawa and L. L. Hench, "AM1 study on infra-red spectra of silica clusters modified by fluorine," Journal of Non-Crystalline Solids, vol. 262, no. 1-3, pp. 264-270, 2000.

[38] G. Odian, Principles of Polymerization, John Wiley \& Sons, 4th edition, 2004.

[39] X. K. Zhao, S. Xu, and J. H. Fendler, "Semiconductor particles formed at monolayer surfaces," Langmuir, vol. 7, no. 3, pp. 520524, 1991.

[40] M. S. F. Danúbia, A. L. Thaysa, A. S. A. Kátia, and S. A. Elmo, "Sonochemical synthesis of cooper II sulfide nanoparticles and their use as radiolytic stabilizer in polyvinyl chloride matrix," in Proceedings of the International Nuclear Atlantic Conference (INAC '13), Recife, Brazil, 2013.

[41] P. Zhang, Y. Wang, W. Chen, H. Yu, Z. Qi, and K. Li, "Preparation and solution characteristics of a novel hydrophobically associating terpolymer for enhanced oil recovery," Journal of Solution Chemistry, vol. 40, no. 3, pp. 447-457, 2011.

[42] X.-J. Xu and F. Chen, "Semi-continuous emulsion copolymerization of butyl methacrylate with polymerizable anionic surfactants," Polymer, vol. 45, no. 14, pp. 4801-4810, 2004.

[43] O. Okay, "Self-healing hydrogels formed via hydrophobic interactions," in Supramolecular Polymer Networks and Gels, vol. 268 of Advances in Polymer Science, pp. 101-142, Springer, 2015.

[44] Z. Chen, X. Zhao, Z. Wang, and M. Fu, "A comparative study of inorganic alkaline/polymer flooding and organic alkaline/ polymer flooding for enhanced heavy oil recovery," Colloids and Surfaces A: Physicochemical and Engineering Aspects, vol. 469, pp. 150-157, 2015.

[45] Y.-H. Dai, F.-P. Wu, M.-Z. Li, and E.-J. Wang, "Properties and influence of hydrophobically associating polyacrylamide modified with 2-phenoxylethylacrylate," Frontiers of Materials Science in China, vol. 2, no. 1, pp. 113-118, 2008.

[46] J. Li, F.-P. Wu, and E.-J. Wang, "Hydrophobically associating polyacrylamides modified by a novel self-associative cationic monomer," Chinese Journal of Polymer Science, vol. 28, no. 2, pp. 137-145, 2010.

[47] W. Xue, I. W. Hamley, V. Castelletto, and P. D. Olmsted, "Synthesis and characterization of hydrophobically modified polyacrylamides and some observations on rheological properties," European Polymer Journal, vol. 40, no. 1, pp. 47-56, 2004.

[48] L. Ye, R. Huang, J. Wu, and H. Hoffmann, "Synthesis and rheological behavior of poly[acrylamide-acrylic acid-N-(4butyl)phenylacrylamide] hydrophobically modified polyelectrolytes," Colloid and Polymer Science, vol. 282, no. 4, pp. 305313, 2004.

[49] A. Bera, A. Mandal, K. Ojha, and T. Kumar, "Characterization of surfactant stabilized nanoemulsion and its use in enhanced oil recovery," in Proceedings of the SPE International Oilfield Nanotechnology Conference and Exhibition, SPE-155406-MS, Society of Petroleum Engineers, Noordwijk, The Netherlands, June 2012. 

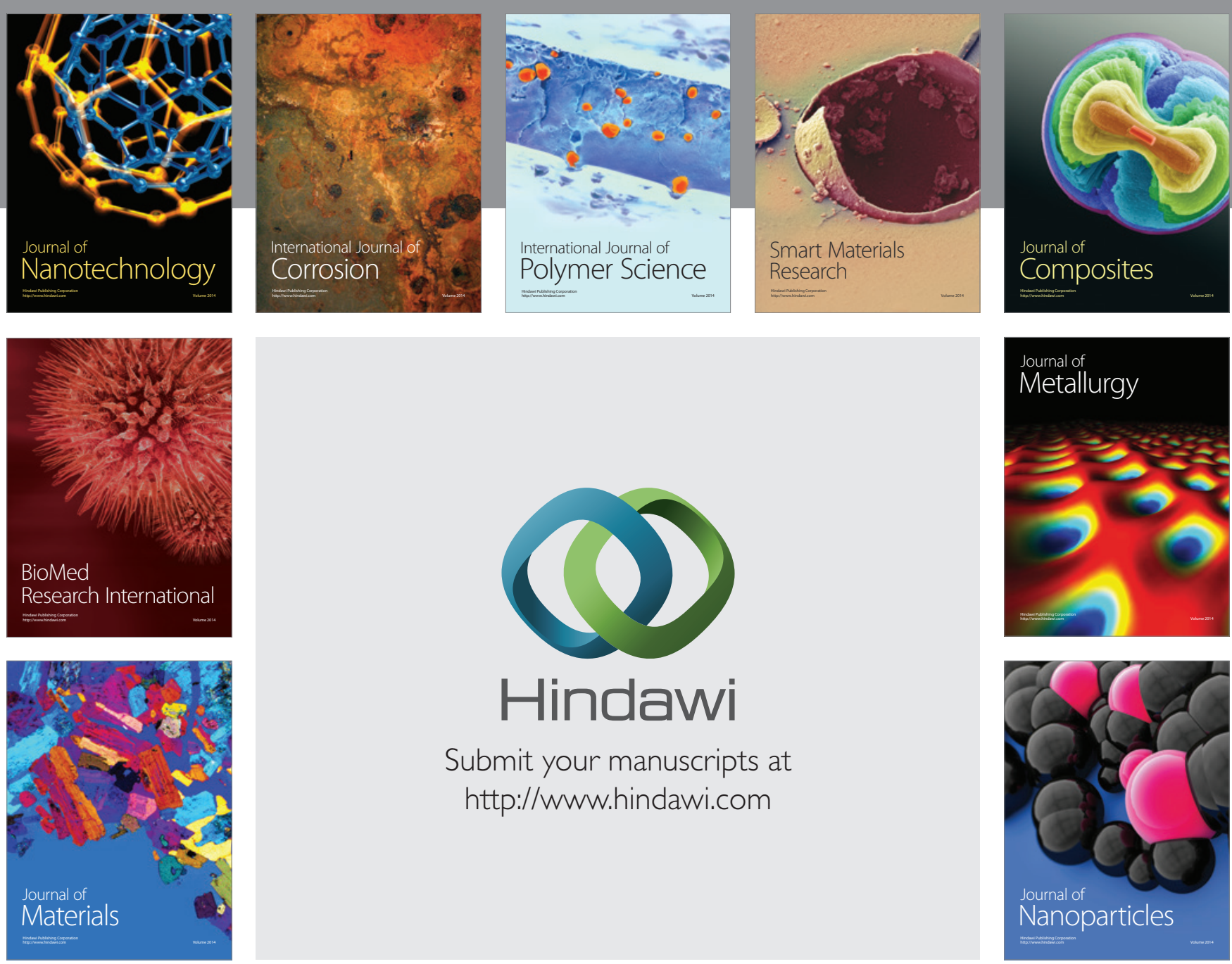

Submit your manuscripts at http://www.hindawi.com
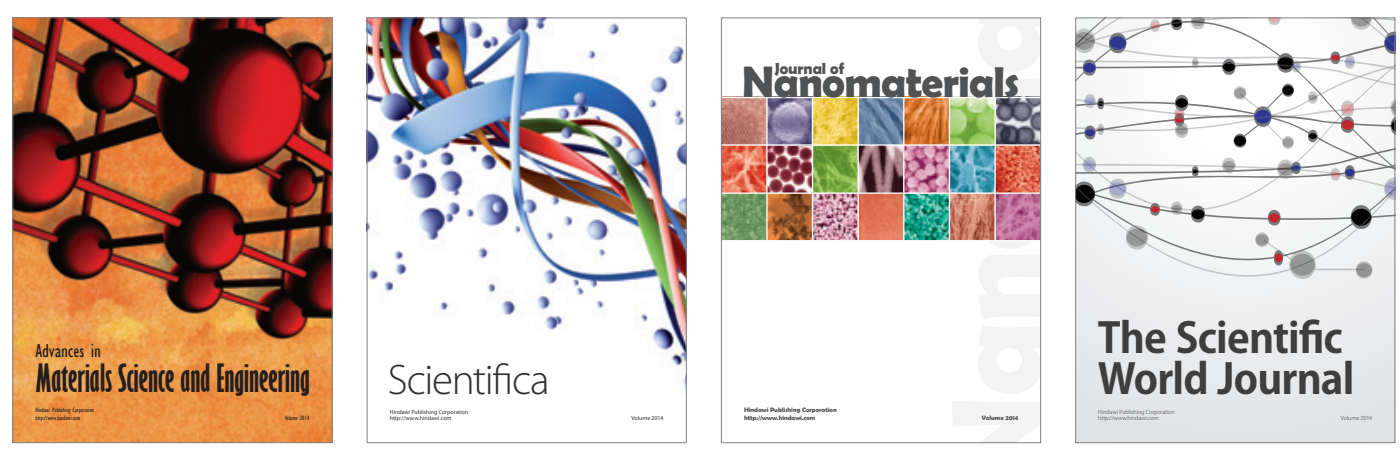

\section{The Scientific World Journal}
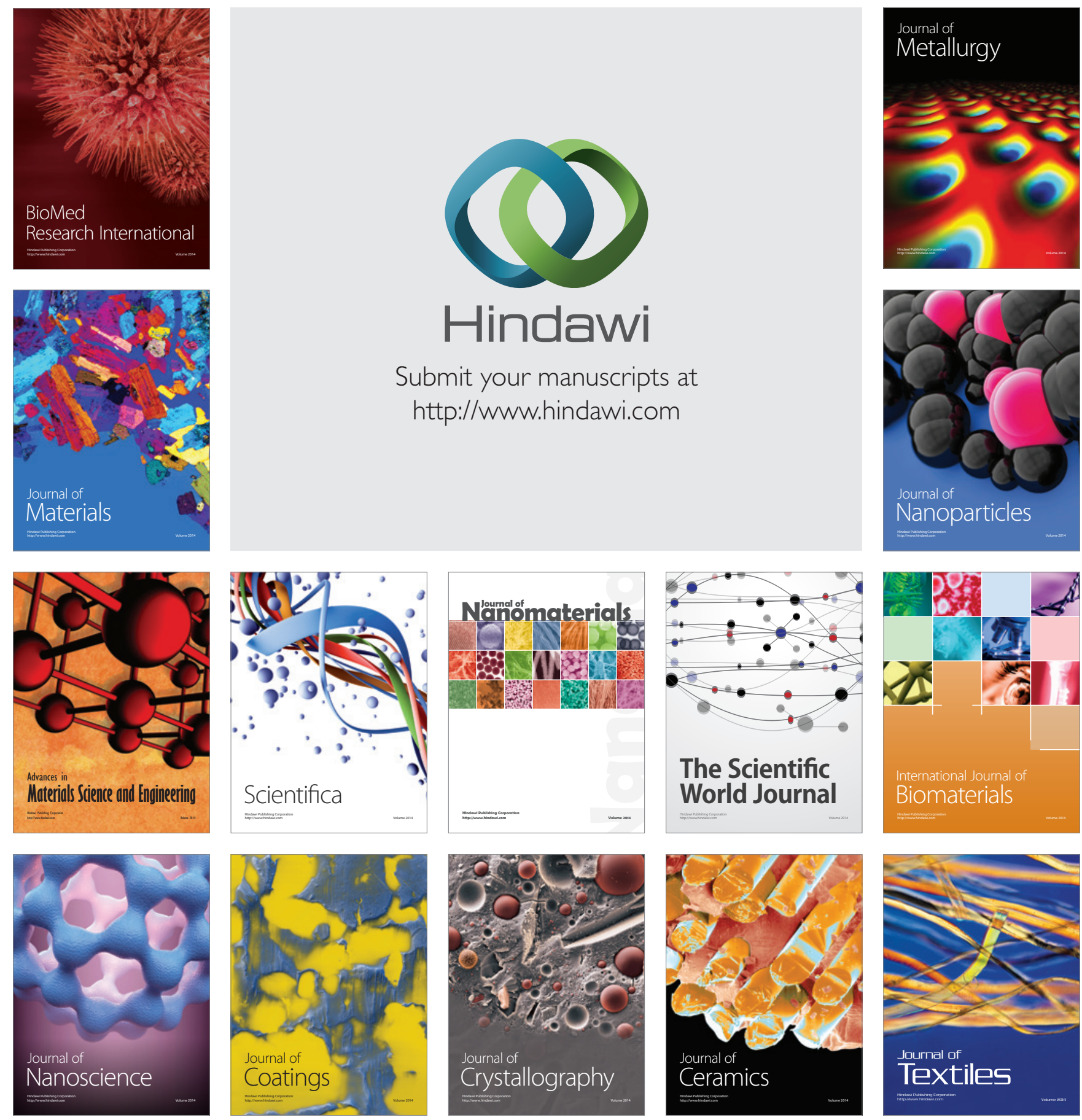